\title{
Separators and electrolytes for rechargeable batteries: Fundamentals and perspectives
}

\author{
${ }^{1}$ TU Bergakademie Freiberg, Institute of Experimental Physics, Leipziger Str. 23, 09599 Freiberg, Cermany, E-mail: \\ Tina.Nestler@physik.tu-freiberg.de \\ ${ }^{2}$ Materials for Energy Conversion, Swiss Federal Laboratories for Materials Science and Technology (Empa), Überlandstrasse \\ 129, 8600 Dübendorf, Switzerland, E-mail: elsa.roedern@empa.ch \\ ${ }^{3}$ Institute of Solid State Chemistry and Mechanochemistry Siberian Branch of the Russian Academy of Sciences, Kutateladze \\ 18,630128 Novosibirsk, Russia, E-mail: uvarov@solid.nsc.ru \\ ${ }^{4}$ TU Bergakademie Freiberg, Institute of Experimental Physics, Leipziger Str. 23, 09599 Freiberg, Germany, E-mail: \\ juliane.hanzig@physik.tu-freiberg.de \\ ${ }^{5}$ Technische Universitt Berlin, Sekretariat TIB 4/2-1, Gustav-Meyer-Allee 25, 13355 Berlin, Germany, E-mail: elia@tu-berlin.de \\ ${ }^{6}$ TU Bergakademie Freiberg, Institute of Experimental Physics, Leipziger Str. 23, 09599 Freiberg, Cermany, E-mail: \\ mateo.devivanco@physik.tu-freiberg.de
}

\begin{abstract}
:
Separators and electrolytes provide electronic blockage and ion permeability between the electrodes in electrochemical cells. Nowadays, their performance and cost is often even more crucial to the commercial use of common and future electrochemical cells than the chosen electrode materials. Hence, at the present, many efforts are directed towards finding safe and reliable solid electrolytes or liquid electrolyte/separator combinations. With this comprehensive review, the reader is provided with recent approaches on this field and the fundamental knowledge that can be helpful to understand and push forward the developments of new electrolytes for rechargeable batteries. After presenting different types of separators as well as the main hurdles that are associated with them, this work focuses on promising material classes and concepts for next-generation batteries. First, chemical and crystallographic concepts and models for the description and improvement of the ionic conductivity of bulk and composite solid electrolytes are outlined. To demonstrate recent perspectives, research highlights have been included in this work: magnesium borohydride-based complexes for solid-state $\mathrm{Mg}$ batteries as well as all-in-one rechargeable $\mathrm{SrTiO}_{3}$ single-crystal energy storage. Furthermore, ionic liquids pose a promising safe alternative for future battery cells. An overview on their basic principles and use is given, demonstrating their applicability for Li-ion systems as well as for so-called post-Li chemistries, such as Mg-and ت Al-ion batteries.

Keywords: solid electrolytes, ionic liquids, Mg-ion battery, Al-ion battery, solid electrolyte-electrode interface, separators

DOI: $10.1515 /$ psr-2017-0115
\end{abstract}

\section{Introduction}

While the electrodes are the electrochemical active materials that determine the overall reachable energy density and efficiency, the choice of the separator and the electrolyte is not less important. In fact, they mainly influence cycle stability and safety. For instance, rechargeable Li cells commonly utilize polymeric separators whose pores are filled with liquid flammable electrolyte, since it is cheap and guarantees high power densities. However, problems arise from different failure mechanisms during cell operation, which can affect the integrity and functionality of these separators. In the case of excessive heating or mechanical damage, polymeric separators can become an incalculable security risk [1]. In the recent past, this impaired the reputation of companies as Tesla [2] and caused losses of billions of euros for Samsung [3]. In order to minimize these risks, the so-called composite separators have been suggested that, however, still struggle with problems due to the organic electrolyte. A higher temperature stability and reliable battery operation can be achieved with full ceramic electrolytes. Such solid electrolytes have been commercially mainly used for high-temperature operation systems up to now, due to generally low ion conductivities at room temperature. The scientific progress in the 
last years and the demand on higher safety, cycleability and volumetric energy density pushes the release of allsolid-state Li cells. Starting with a short topical overview of available separator materials and technologies by summarizing the authors previous review on this topic [1], different solid electrolyte classes and approaches to improve their performance are illuminated here. Furthermore, ionic liquids (ILs) offer high safety and improved cell performance and are thus discussed here as alternative for conventional electrolytes in Li-ion batteries, as well as enabler for post-lithium systems.

\section{Fundamentals and categorization}

The oldest known separator materials originate from the first experiments by A. Volta at the end of the eighteenth century. Volta demonstrated the generation of electricity from his voltaic pile using a cloth as separator, which was soaked in a sodium chloride solution [4]. Later, a variety of other separator materials became known, manufactured from cedar shingles and sausage casings, cellulosic papers, wood, cellophane, nonwoven fabrics, foams or microporous polymeric membranes [5-8]. The development of dedicated separators in the second half of the twentieth century was particularly driven by the emerging chemical industry [8]. A detailed overview of separator materials and technologies for batteries is given by Arora et al. [7] and Daniel and Besenhard [8]. A review, dedicated to the technology of Li-ion batteries only, has been published by Huang [9].

The term separator emphasizes its functionality to spatially isolate the anode from the cathode. Its function is to prevent electric contact of the electrodes, which would cause self-discharge, but simultaneously allows ion flow as basis for energy delivery. The ion flow can be conducted by the separator itself or by liquid electrolytes that fill the pores of a separator membrane. Thus, in this regard, separators can be categorized as ion conductive (solid electrolytes) or ion permeable (previous membranes) (Figure 1). This presented subdivision is based on characteristics such as physical properties, crystallographic features, morphology and composition and has been already published in Ref. [1]. Other separator categorizations can be found elsewhere [7].

Prominent examples of the first category in Figure 1 are industrially produced microporous films made from polymers as polypropylene (PP), polyethylene (PE) or polytetrafluoroethylene (PTFE), naturally abundant materials (e.g. cellulose [10] or rubber [7]), as well as nonwovens. Nonwovens are defined as sheets, webs or matts manufactured from fibres that are bonded by adhesion, cohesion, chemical bonds, friction or heat treatment. However, paper and woven, sewn or tufted products are excluded [7]. Commercially used nonwovens have been made of PE, PTFE, polyethylene terephthalate (PET) or polyvinylidene difluoride (PVDF), mainly produced by a wet-laid process [9]. In commercial batteries, separators made from microporous polymeric films dominate [11], which are filled with Li salts in organic solvents. As these materials and production methods are well known [7], in the following paragraphs, the focus will be on the emerging technologies and compounds in the field of solid electrolytes and ILs instead. 


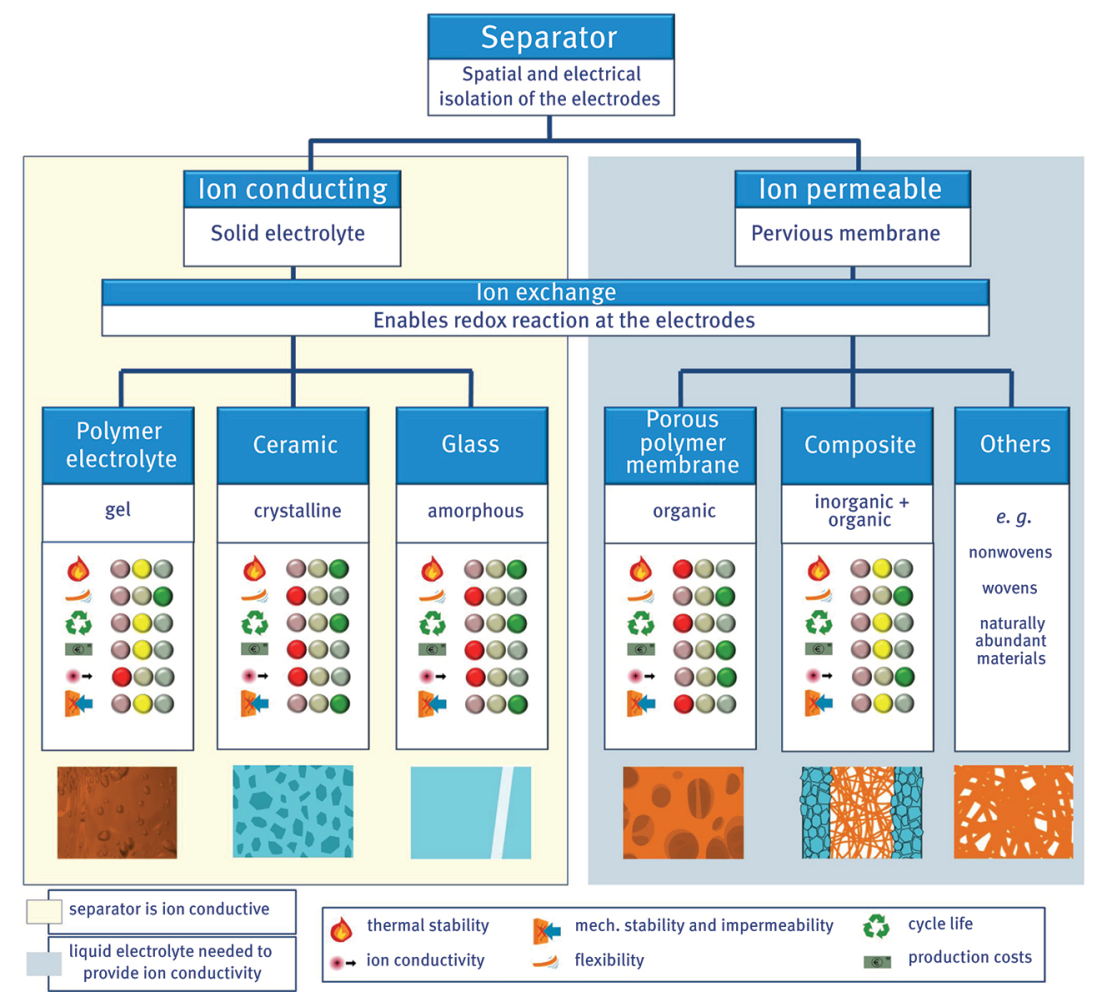

Figure 1: Categorization scheme of separator materials. A 'traffic light system' denotes advantages and disadvantages of the respective materials. Reprinted from Ref. [1], with the permission of AIP Publishing.

In a more detailed view, separators should fulfil a set of specifications. On the one hand, they should preferably enable good ion conductivity to ensure high energy and power densities. For example, the ion conductivity of polymer membranes, based on poly(vinylidene fluoride-co-hexafluoropropylene) (PVDF-HFP) co-polymer hosts, filled with liquid electrolyte is $3.5 \cdot 10^{-3} \mathrm{~S} / \mathrm{cm}$ for Li-ion battery systems at room temperature [12]. On the other hand, separators should exhibit an insignificant electronic conductivity to prevent self-discharge. For instance, a typical value of the PVDF electronic conductivity is $10^{-13} \mathrm{~S} / \mathrm{cm}$ [13]. For the common case of ion permeable separators, the ion conductivity greatly depends on the porosity of the separator material and the soaked in electrolyte, respectively [12]. Furthermore, the ability of efficient wetting with the liquid electrolyte is crucial. Additional conditions have to be met in order to ensure a reliable and safe cell operation, which apply to every type of separator:

- chemically inert towards the electrolyte and the electrodes (resistance to oxidation/reduction),

- sufficient puncture and tensile strength,

- bendability,

- structural integrity over the operating temperature range of the electrochemical cell,

- prevention of thermal runaways in the case of a short-circuited battery.

The term thermal runaway denotes the situation, when an increased temperature leads to the release of thermal energy, which in turn, accelerates the underlying process. For instance, production failures can lead to tiny short circuits in battery cells. These spots will experience extremely high current densities that can lead to the destruction (melting) of the surrounding separator material and thus even higher current flows. This positive feedback mechanism may eventually result in temperatures that are sufficient to inflame organic electrolytes and cause explosions of sealed batteries.

From the production point of view, the most important properties are mechanical stability and simultaneous bendability, which are needed to let separators withstand the cell assembly process, as well as the volume changes of up to $300 \%$ in case of operating Li-ion batteries [14]. In order to increase the power and energy density of batteries, the thickness of the separator is reduced to a minimum, which can compromise mechanical stability and structural integrity. Different failure mechanisms, as the growth of metallic dendrites or chemical attack and oxidation, may lead to the perforation of the separator and finally a short circuit and potentially thermal runaway [15]. 
Depending on the particular storage chemistry and technology, separators are exposed to different stress levels affecting the separator properties and thus cell performance. First of all, changes in environmental conditions can be mentioned, e.g. variations in temperature of up to $100{ }^{\circ} \mathrm{C}$, as is typical for the operation of lead-acid batteries in automobiles. Li-ion cells can reach temperatures of up to $65^{\circ} \mathrm{C}$ [16] during discharge, whereas in the case of a short circuit a temperature increase of even more than a $100{ }^{\circ} \mathrm{C}$ within a few seconds may occur [17]. For the operation of sodium-sulfur batteries or high-temperature solid oxide fuel cells, temperatures of around $30{ }^{\circ} \mathrm{C}$ [18] and $\mathrm{T}>500^{\circ} \mathrm{C}$ [19], respectively, are necessary for normal operation, so that high-temperature stability of the separator is required.

With regard to reports about burning electric vehicles [2] and smart-phones [3], the safety of battery systems has turned into focus even more. One strategy to improve fire safety is to utilize high melting temperature polymers, such as polyamide and polyimide, or the combination of different polymers [9]. The latter could prevent thermal runaways by improving the shutdown ability of the separator while simultaneously sustaining mechanical integrity [9]: If the battery overheats during operation, the polymer with the lower melting point softens and closes the pores of the polymer membrane, thus shutting down the ion conduction and thus battery operation. Simultaneously, the polymer with the higher melting point ensures stability and suppresses short circuits. However, the shutdown is often incomplete and does not block all conductivity. Thus, the cell temperature may continue to rise, which further degrades the stability of the separator. An option to minimize the risk of thermal damage of polymer-based separators is the blending or coating with ceramic particles as $\mathrm{Al}_{2} \mathrm{O}_{3}$, $\mathrm{SiO}_{2}$ and $\mathrm{ZrO}_{2}[11,15,20]$. These materials are termed as composite separators or ceramic enhanced separators [9]. Reported advantageous properties are short circuit prevention up to $220^{\circ} \mathrm{C}$ [21] and negligible shrinkage at high temperatures [15], excellent wettability and comparable high thermal conductivity. The latter promotes fast heat dissipation, preventing damage of the electrodes [9, 15, 22]. Additionally, a higher overcharge abuse tolerance was observed.

Even though the risk of a thermal damage is significantly reduced by composite ceramic separators, a hightemperature use is still limited by the melting point of the organic matrix and degradation mechanism connected to the liquid electrolyte. Solid ion conductive separators, in contrast, eliminate the risk of thermal runaways, are less prone to side reactions with other battery components and also allow for high-voltage electrodes. Thus, they have become attractive for the next generation of Li cells $[23,24]$. These materials can be subdivided into polymer, ceramic and glass solid electrolytes and will be thoroughly discussed here.

In summary, a thorough selection of separator materials and their careful processing during fabrication and cell assembly play a key role in the operation of electrochemical storage devices. The ideal separator has to be selected with regard to the electrolyte and electrode requirements and the field of application. There will often be a trade-off between high power/energy density and a long and safe service life with constantly high coulomb efficiencies.

\section{Solid electrolytes}

Solid electrolytes are materials with fast ionic transport of one ionic species, while there is no or no significant electronic conductivity. ${ }^{1}$ Fast ionic conductivity at ambient temperatures in solids was found for the first time in $\alpha$-AgI [25] at the beginning of the last century. As has been already stated in Ref. [1], today, there is a broad variety of single-crystalline, polycrystalline and amorphous materials to choose from, which most commonly belong to the group of oxides (e.g. $\left.\beta-\mathrm{Al}_{2} \mathrm{O}_{3}[18,26]\right)$, sulfides (e.g. $\mathrm{Li}_{10} \mathrm{GeP}_{2} \mathrm{~S}_{12}$ [27]) and phosphates (e.g. $\mathrm{LiZr}_{2} \mathrm{P}_{3} \mathrm{O}_{12}$ [28]). There are numerous reports on materials that conduct mono- and divalent ions such as $\mathrm{Ag}^{+}$ [29-31], $\mathrm{Na}^{+}[18,32-35], \mathrm{Li}^{+}[36,37], \mathrm{K}^{+}[38], \mathrm{H}_{3} \mathrm{O}^{+}[39], \mathrm{Tl}^{+}[40], \mathrm{NH}_{4}^{+}$[41], $\mathrm{Cu}^{+}[42], \mathrm{F}^{-}[43-45], \mathrm{OH}^{-}[46], \mathrm{O}^{2-}$ $[39,47,48], \mathrm{Ca}^{2+}[49], \mathrm{Sr}^{2+}[49,50], \mathrm{Ba}^{2+}[49,50], \mathrm{Zn}^{2+}[49,51], \mathrm{Cd}^{2+}[49], \mathrm{Pb}^{2+}[49]$ and $\mathrm{Hg}^{2+}$ [49]. In contrast, compounds for tri- or even tetravalent ions as $\mathrm{Gd}^{3+}[52-54], \mathrm{Al}^{3+}$ [55] or $\mathrm{Zr}^{4+}$ [55] are controversial [56, 57] and not unequivocally proven, which will be briefly discussed below.

Solid electrolytes are of prime importance for batteries, fuel cells and sensors. The recent advent of solid electrolytes, however, can only be explained with regard to the challenges faced by current Li and emerging post-Li systems. Currently, small mobile consumer electronics, hybrid and electric cars and even some stationary batteries for the storage of renewable energies employ Li-ion batteries that utilize liquid electrolytes with flammable organic solvents. Within the last years, this caused occasionally fire or even explosion, damaging the reputation and profit of well-known companies [2,3]. The safety of solid electrolytes is expected to be guaranteed, since they are mostly non-flammable. The even more important driver for the research on solid electrolytes is the demand on batteries with higher energy densities and longer lifetime for the development of mobile devices and especially the spread of electric vehicles. As already mentioned, solid electrolytes are much less vulnerable to cause side reactions as conventionally used carbonate-based electrolytes permit only 
negligible self-discharge, and cannot leak, boil, freeze or ignite. All-solid-state batteries hold a promise to increase both the cycle life due to their stability [58-60] and also the energy density because of generally higher electrochemical windows. Both aspects allow a more flexible choice of electrodes with higher voltages or capacity, as pure Li anodes [28] and polyanion cathodes [61]. Furthermore, metal-air batteries [37, 62], which are becoming especially important for EVs, could benefit from solid electrolytes, as they would prevent the reaction between the metal anode and the electrolyte or unwanted side products [62,63]. Another advantage from a technical point of view is that there is no need for the time-consuming, electrolyte-filling step during battery assembly [64]. Additionally, simplified battery structures can be designed: In the case of cell stacks, all batteries can be mounted in one container, instead of connecting individual containers as necessary for the use of liquid electrolytes [37].

On the other hand, the rigid nature of ceramics poses problems to cell winding and assembly. It also leads to stress during charge and discharge due to the associated volume change of the electrodes, which can result in cracking of the separator and in delamination of the sintered electrode layers. It should be noted that this issue is less relevant for intercalation electrodes, as they do not cause large volume changes [37]. Moreover, extremely thin solid electrolyte separators $(<0.5 \mu \mathrm{m})$ can become flexible enough for winding. Further disadvantages of ceramic separators are the reduced electrode/electrolyte contact area and the overall lower ion conductivity at room temperature in comparison to liquid electrolytes. However, e.g. in the case of Li ions, a ceramic material $\left(\mathrm{Li}_{10} \mathrm{GeP}_{2} \mathrm{~S}_{12}\right)$ with a conductivity comparable to conventional organic electrolytes $\left(10^{-2} \mathrm{~S} / \mathrm{cm}\right)$ has been found [27]. Moreover, a strategy to avoid the high-resistance problem of the electrode/solid electrolyte interface (SEI) and to simultaneously keep the high-temperature stability is to use an IL as wetting agent, which has been already demonstrated by Kim et al. [65].

Plenty of Li-conducting materials have been investigated so far, and there has been a significant progress recently. Several companies promote the application of solid electrolytes in the next generation of Li batteries in electronic devices, including Cymbet, Front Edge Technology, Infinite Power Solutions, Sakti3, SEEO, Toyota, Planar Energy, SolidEnergy Systems, Quantum Scape, etc. Nevertheless, only a few compounds meet the required properties for commercialization simultaneously: sufficient room temperature conductivity, lowresistance grain boundaries and chemical inertness towards the electrodes, low production cost and environmental impact [66]. While for microbatteries they have been already commercialized, all-solid-state batteries for portable devices or automotive applications are still in R\&D or pilot state. In the following sections, we point out the most important principles of crystallographic material design for solid electrolytes to hint on potential research directions to overcome current hurdles.

\subsection{Ionic conduction in solids: Fundamentals and crystallographic requirements}

Fast ion transport requires high concentrations of defects (intrinsic or extrinsic), as the ions need empty spots to jump into. The motion of ions in solids can occur via interstitial sites, vacancies or along grain boundaries. The transport of point defects can be described as random walk, giving a tracer or self-diffusion coefficient of the ions (e.g. in [67])

$$
D^{*}=\frac{\Gamma<r^{2}>}{2 d} f,
$$

where $r$ is the jump distance between occupied and vacant site, $\Gamma$ is the frequency of ion hopping between two sites and $d$ is the dimensionality of ion conduction $(1,2$ or 3$)$. Additionally, a correlation factor $f(1 \leqslant f>0)$ is needed, as the direction of successive jumps is not perfectly random. This fact can be easily understood by imaging a tracer ion that just jumped into a vacancy: the chance of the reverse jump is much higher than into the partially occupied other neighbouring sites. Thus, $f$ needs to take into account the topology of the path, the mechanism and also the defect density $[68,69]$. Furthermore, in crystals, the diffusion can be imagined as thermally activated Brownian motion of ions across a periodic landscape of potential barriers. Generally, the ion conductivity increases with higher temperatures. On the one hand, the concentration of charge carriers may be enhanced due to the additional thermal energy that might be needed for defect creation in the first place. On the other hand, the ions possess more energy to overcome the activation barrier $E_{\text {mig }}$ for ion hopping inside the migration channel. Both the hopping frequency $\Gamma$ and the concentration of charge carriers $c$ thus follow Arrhenius law [70, 71]:

$$
\begin{gathered}
\Gamma=p v e^{-\frac{E_{\mathrm{mig}}}{k_{\mathrm{B}} T}}, \\
c=c_{0} e^{-\frac{E_{\mathrm{f}}}{k_{\mathrm{B}} T}},
\end{gathered}
$$


with $k_{\mathrm{B}}$ being the Boltzmann constant, $T$ the absolute temperature, $p$ the number of potential jumping paths, $c_{0}$ the charge carrier concentration at infinite temperature and $E_{\mathrm{f}}$ the defect/charge carrier formation energy. The hopping attempt frequency $v$ can be estimated by the Debye frequency. Finally, these considerations connect to the measured ion conductivity $\sigma$ within an electric field via the Nernst-Einstein/Einstein-Smoluchowski relation

$$
\sigma=\frac{D^{*} H_{R} c Q^{2}}{k_{\mathrm{B}} T},
$$

where $Q$ is the electric charge of the conduction ion and $H_{R}$ is the Haven ratio, which is close to 1 [69]. This factor is needed to include the deviation of $D^{*}$ describing an undirected diffusion to the rather concerted walk: When an electric field is applied, the ions perform successive jumps, since they cannot only jump in the nearest vacant site, but also in (formerly) occupied sites. By finally combining Eqs. 1-4, it can be shown that the conductivity $\sigma$ follows the temperature behaviour

$$
\sigma=\frac{\sigma_{0}}{T} e^{-\frac{E_{\mathrm{a}}}{k_{\mathrm{B}} T}},
$$

with $\sigma_{0}$ combining the described constants and $E_{\mathrm{a}}=E_{\mathrm{mig}}+E_{\mathrm{f}}$. Thus, by measuring the temperaturedependent conductivity and plotting $\log \sigma$ versus $1 / T$, one can determine the activation energy for ion conduction $E_{\mathrm{a}}$, which is in the range of $0.25 \mathrm{eV}$ to $1 \mathrm{eV}$ for sodium conductors [18]. Such plots are shown for several solid Li conductors and organic liquid electrolytes in Figure 2.

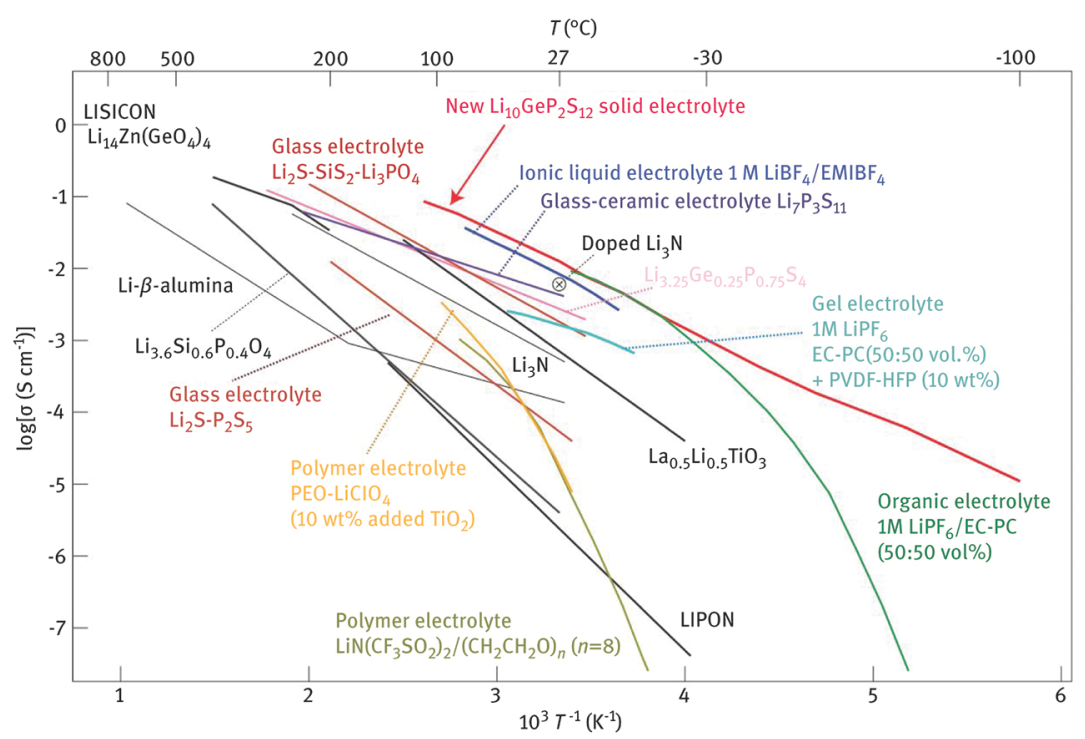

Figure 2: Thermal evolution of ion conductivity of Li solid electrolytes, organic liquid electrolytes, polymer electrolytes, ionic liquids and gel electrolytes (data sources are indicated in [27]). $\mathrm{Li}_{10} \mathrm{GeP}_{2} \mathrm{~S}_{12}$ shows an ion conductivity that is comparable to those of the liquid electrolytes at room temperature and higher at lower temperatures, which is important for the application in electric cars. Reprinted by permission from Macmillan Publishers Ltd: Nature materials [27], copyright 2011.

In the following paragraphs, chemical and crystallographic conditions that facilitate or enhance ionic conductivity in solid materials in general are discussed. Main parts of this discussion have been already published by the authors in [57]. To improve ion conductivity, two types of doping have been applied to solid electrolytes: homogeneous and heterogeneous doping. For the broadly used homogeneous doping, small amounts of foreign atoms are dissolved in the compound and substitute intrinsic ions. In this way, aliovalent ions can be incorporated in the ion conductor. Depending on the charge difference between the doped and replaced ion, interstitials or vacancies are formed to maintain electroneutrality. Tailored homogeneous doping can lead to higher conductivity, since either vacancies or mobile charge carriers needed for ion migration are created or $E_{\mathrm{a}}$ is lowered [45, 72-75]. For cation conductors, doping the cation sublattice, either with immobile (see i.e. in [74]) or mobile ions $[72,73,75]$, can be used to engineer the site energies and thus hopping barriers. An instructive example for the latter case is the garnet-type Li conductor $\mathrm{Li}_{3+x} \mathrm{La}_{3} \mathrm{M}_{2} \mathrm{O}_{12}(\mathrm{M}=\mathrm{Te}, \mathrm{Nb}, \mathrm{Zr})$ [73]: Ab initio calculations reveal that the activation energy sensitively depends on the amount of $\mathrm{Li}$, as the occupancy of the $\operatorname{Li}(1)$ and $\operatorname{Li}(2)$ site depends on the overall Li concentration. These occupancies, in turn, determine which ion migration routes are dominant. Higher Li occupancies favour a migration path with lower activation energy (Figure 3), which is consistent with experimental findings [73]. Furthermore, doping of the counterion sublattice can be utilized as well. For example, the number of point defects that participate in ionic motion in the fluoride-ion conductor $\mathrm{BaF}_{2}$ is increased, when it is doped with trivalent cations [45]. 

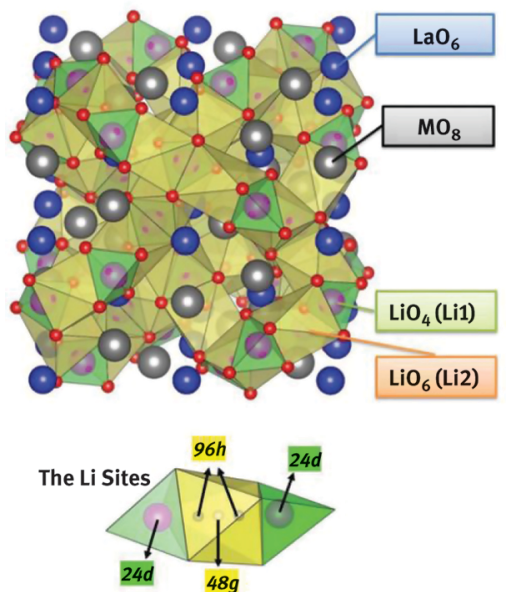

(a)

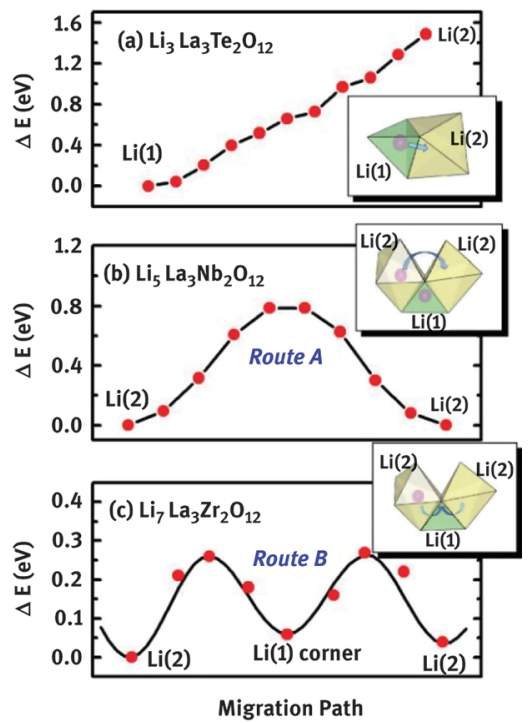

(b)

Figure 3: Left: Crystal structure of garnet-type Li-ion conductors, showing two different Wyckoff positions for $\mathrm{Li}(\mathrm{Li}(1)$ and $\mathrm{Li}(2)$ ). Right: Calculated energy barriers for the dominant Li migration routes (blue arrows) for garnet-type compounds with different $\mathrm{Li}$ concentration and resulting occupancies of $\operatorname{Li}(1)$ and $\mathrm{Li}(2)$ : (a) In the case of low Li concentrations, the tetrahedral sites are occupied. In order to migrate through the crystal, the ions have to hop to the neighbouring octahedral site, which shows a significantly higher site energy and is thus not likely. (b) For higher Li concentrations, Li ions already occupy the octahedral position and the migration can occur via the interstice between the octahedrons. (c) A very high Li stoichiometry results into vacancies in the tetrahedral site and different site energies in comparison to (a) and (b) due to Li-Li interaction. Starting from the octahedral site, $\mathrm{Li}$ is thus allowed to move via the tetrahedral position, bridging a lower activation energy. Reprinted figures with permission from [73].

The second approach, heterogeneous doping, is typically realized by creating interfaces to other electrolytes or insulators or even to the same compound. In most cases, grain boundaries in polycrystalline materials increase the resistance. However, if the interfaces provide appropriate defects or even better paths for ion hopping due to favourable ion redistribution in the space charge region, the conductivity can be enhanced in comparison to the bulk material (e.g. [30, 45, 76-80]). For instance, this is the case for the grain boundaries in the already mentioned $\mathrm{F}^{-}$conductor $\mathrm{BaF}_{2}$ [45]. As an example for a two-phase system, $\mathrm{AgCl}-\mathrm{Al}_{2} \mathrm{O}_{3}$ shows increased $\mathrm{Ag}^{+}$ conductivity in comparison to bulk $\mathrm{AgCl}$, due to an increased amount of cation defects at the interface [30]. For an overview on this topic and comprehensive discussion, the reader is referred to Ref. [77]. More recent studies illuminate the role of lattice-mismatch strain [78] as well as dislocations [80] for increased oxygen ion conductivity.

For solid electrolytes for $\mathrm{Li}$ and other monovalent and divalent ions, numerous works and reviews have been published discussing favourable crystal structure motifs for ion migration and how doping is used to improve the ion diffusivity in inorganic solids (e.g. [75, 76, 81-88]). From all these studies as well as heuristic considerations, several factors can be extracted that provide high ion mobility in solids:

1. High symmetry, low occupancy: Vacant sites in close vicinity to each other with no or only small differences of site energies are required, in order not to form high barriers in between. Ideally, they would form a stable 3D network of tunnels, not only to provide ion conductivity in every direction, but also since 1D conductivity can be easily blocked by defects. Such features are commonly found in structures with highly symmetrical space groups and low occupancies of the atomic sites (with high multiplicity) of the mobile species.

2. Right-sized tunnels: The voids that surround the vacant sites and the bottlenecks of the connecting tunnels should be of a suitable (sufficient but also not too large) spatial dimension for the considered migrating ion. That means the formed channel should be smooth without too tight or wide sections and severe coordination changes.

3. Mobile-ion ratio: There should be a balanced ratio of the number of mobile ions and connected vacant sites, which can be optimized e.g. by aliovalent doping.

4. High-valent framework cations: To reduce the energy barrier of the channel that connects the vacant sites, the migration path should be accompanied by preferably screened counterions in the first coordination sphere. Such a screening of attractive interactions can be favoured by ions in the lattice with a higher samesign charge as the considered mobile ion. They may form strong competitive bonds. 
5. Polarizable anions The counterions should be polarizable to further reduce electrostatic interaction with the mobile ions.

As stated in the first point, the sites in the migration channel need to possess similar energies. For instance, fast (/superionic) Li conductors were found to show paths that straightly connect two tetrahedral sites instead of crossing an energetically higher octahedral site [75]. Structures with this feature were found to possess body-centred, cubic like anion frameworks (Figure 4). It was also shown that a higher volume of these anion sublattices, resulting in a higher Li-anion distance, would favour low barriers [75], as coinciding with criteria 2. Hints for the structural design can be also found by looking at insertion materials: Rong et al. [87] discovered for intercalation electrodes that the hopping barrier tends to be lower if the inserted ions occupy sites that do not show their preferred coordination. This means, in the case of Li, octahedral instead of tetrahedral sites. By this way, they already possess a high site energy, which potentially lowers the energetic difference toward the bottleneck they have to pass during diffusion. This is also in good agreement with the example given earlier concerning garnet-type Li conductors [73] (Figure 3). In general, a minimal change of coordination between the stable and intermediate sites appears to be advantageous for high-valent ions [87]. This is why structures with close-packed anion sublattices such as spinels or olivines might be penalized [87], as the change in the local environment during ionic motion is more drastic than for other anionic packings.

(a)

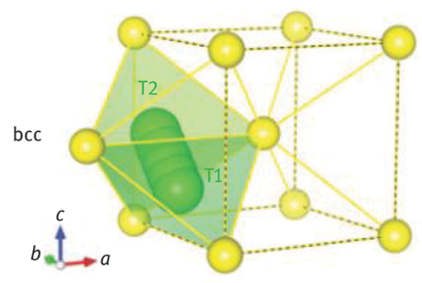

(b)

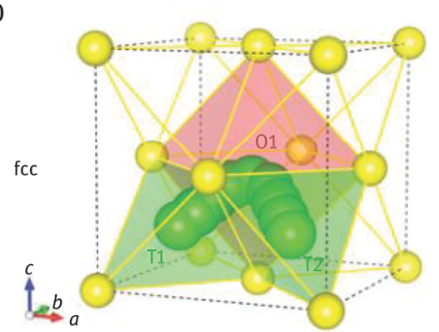

(c)

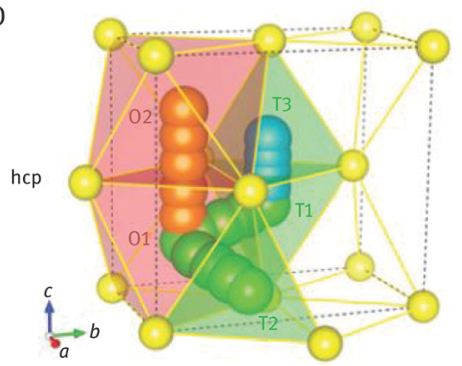

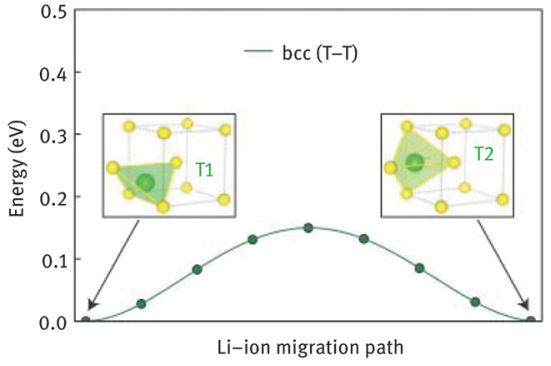

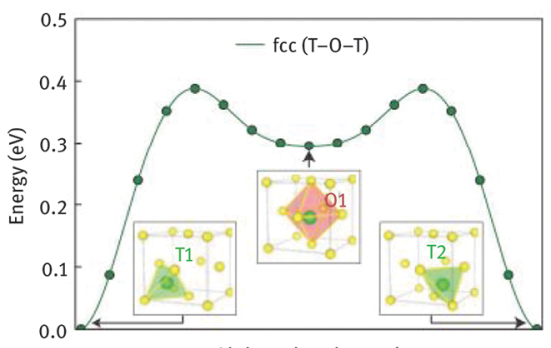

Li-ion migration path

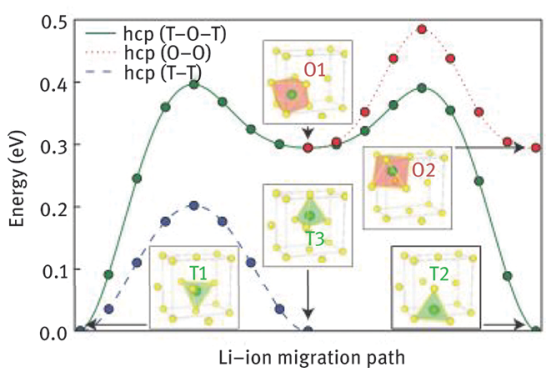

Figure 4: Li-ion migration pathways (left column) in (a) bcc-, (b) fcc- and (c) hcp-type sulfur lattices with the corresponding migration barriers calculated by density functional theory (right column). Different Li paths are coloured red, green and blue, sulfur yellow, $\mathrm{LiS}_{4}$ tetrahedra green and $\mathrm{LiS}_{6}$ octahedra red. Reprinted by permission from Macmillan Publishers Ltd: Nature Materials [75], copyright 2015.

Even though the second criteria (spatial fit of migration channel and mobile ion) might appear logical, for decades it was generally accepted that the mobile ions need to be small to show good conductivity [81] and the wider the opening of the migration channels the better. From this point of view, $\mathrm{Al}^{3+}$ with an effective ion radius of $39 \mathrm{pm}$ in comparison to $59 \mathrm{pm}$ for $\mathrm{Li}^{+}$(both at the coordination number four [89]) would seem to easily migrate through the channels in crystal structures. Many authors indeed argued this property would facilitate finding intercalation compounds (e.g. [90]). However, small size does not guarantee best ion conductivity: Among monovalent ions in $\beta$-alumina, it is not $\mathrm{Li}^{+}$, but the medium-sized $\mathrm{Na}^{+}$and $\mathrm{Ag}^{+}$ions that display the lowest activation barriers (Figure 5). In fact, the small size and thus high charge density of $\mathrm{Al}^{3+}$ is expected to cause trapping in the lattice and at defects due to low polarizability. Indeed, finding materials was revealed to be a tough task, with only one unequivocally identified reversible intercalation material so far [91]. In general, 
a high charge will lead to stronger Coulomb interactions and therefore comparably higher activation energies. Apart from these considerations, how to find a suitable environment for the considered mobile species? Unfortunately, the suitable spatial dimension cannot be simply estimated from the ionic size. For instance, even though $\mathrm{Mg}^{2+}$ and $\mathrm{Zn}^{2+}$ possess almost the same ionic radii (72 pm and $74 \mathrm{pm}$ [89]), very different diffusion barriers have been calculated in the same well-known oxidic intercalation materials (spinel $\mathrm{Mn}_{2} \mathrm{O}_{4}$, olivine $\mathrm{FePO}_{4}, \mathrm{NiO}_{2}, \delta-\mathrm{V}_{2} \mathrm{O}_{5}$ ) [87]. Rong et al. ascribe this to different preferences of the ions for octahedral or tetrahedral sites, which results in opposed preferred topologies of the pathway as described above. The preferred ionic surroundings can be taken into account by bond valence (BV) analysis, as outlined in [92] or [57]. It utilizes the experimental finding that the ideal bond length can be described as depending on the ion-counterion pair and coordination number, applying data-mined constants from the topological analysis of thousands of crystal structures. It can be used to find and evaluate potential migration channels, similarly to the topological analysis by Voronoi Dirichlet partitioning [92].

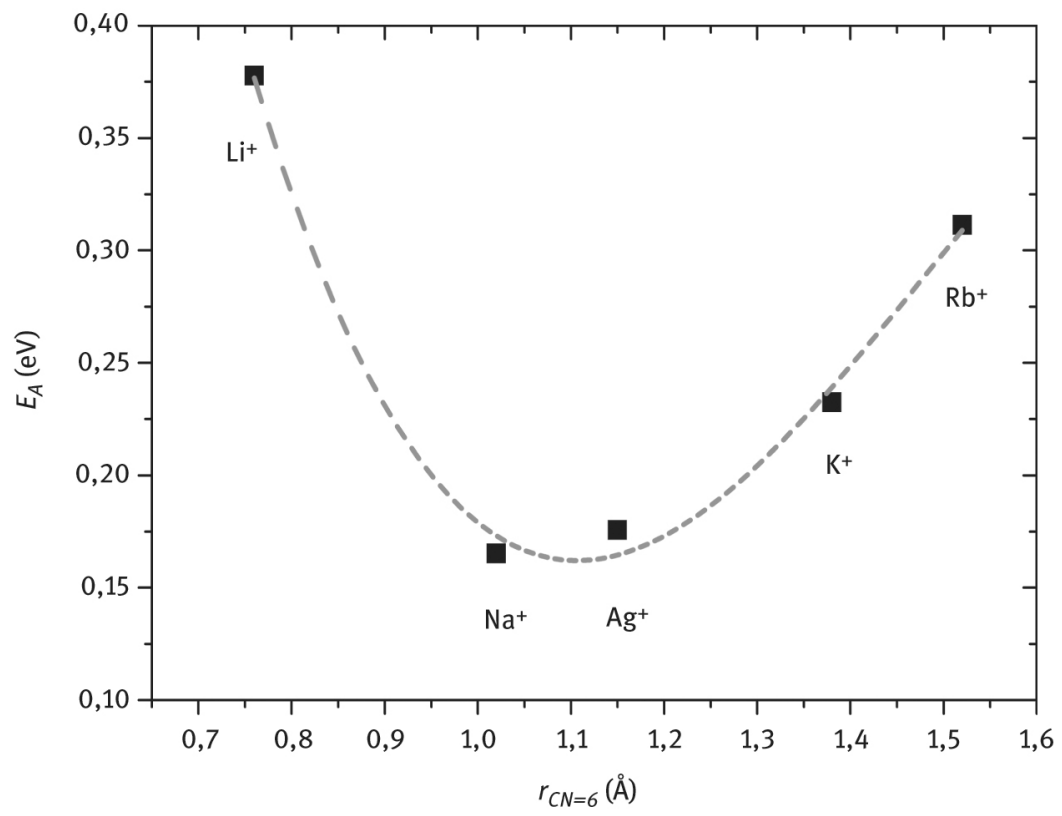

Figure 5: The activation energies $E_{\mathrm{a}}$ for the diffusion of different monovalent ions in $\beta$-alumina [31] versus the effective ionic radii of the respective mobile ions in octahedral coordination $r_{\mathrm{CN}=6}$ [89]. The dashed line is meant to solely serve as guide to the eyes.

The listed criteria are also relevant to the local atomic environment of amorphous or vitreous conductors. Furthermore, they must be met by compounds for high-valent ( $\mid$ charge $\mid>2$ ) solid electrolytes as well. Especially the screening of the attractive coulomb interactions by ions in the lattice with a higher same-sign charge as the considered mobile ion should be an important prerequisite. For cation conductors, this can be achieved by incorporating $\mathrm{W}^{6+}, \mathrm{Mo}^{6+}, \mathrm{Mn}^{4+}, \mathrm{P}^{5+}$ or $\mathrm{Si}^{4+}$. Furthermore, the presence of other ions with a lower net charge in the compound has to be examined critically due to their higher likelihood of migration. These comprehensible but still heuristic considerations, however, could not be conclusively proven so far. In contrast to mono- and divalent species, the rather controversial question, whether trivalent ions can be conducted in crystalline solids, has not been unambiguously clarified yet. As already mentioned, since the higher charge results in increased coulombic interactions, high-valent ions are expected to much more likely stay fixed on their crystallographic site. Nevertheless, the work groups of Farrington [54] and later on Imanaka [55] claimed to have synthesized compounds that are able to conduct trivalent or even tetravalent ions. However, it appears that there is still a lack of direct and unequivocal experimental evidence for this phenomenon. For example, measurements of $\mathrm{X}_{2}\left(\mathrm{BO}_{4}\right)_{3}$-type compounds $(X=\mathrm{Sc}, \mathrm{Al}, \mathrm{In}, \mathrm{Lu}, \mathrm{Yb}, \mathrm{Tm}, \mathrm{Er} ; B=\mathrm{Mo}, \mathrm{W})$ have been interpreted as proving $\mathrm{X}^{3+}$ conduction by Imanaka et al. since $1995[55,93,94]$. However, the performed experiments were not suited to doubtlessly demonstrate that. Eventually, several theoretical simulations [95-100] as well as experiments [56] employing the more reliable Tubandt method proved this wrong and showed anion, dominantly $\mathrm{O}^{2-}$, conduction instead [56]. A comparison between the potential pathways/accessible sites for different ionic species calculated by BV and molecular dynamics is shown in Figure 6, showing that $\mathrm{Sc}^{3+}$ conduction is rather improbable in $\mathrm{Sc}_{2}\left(\mathrm{WO}_{4}\right)_{3}$ [96]. Up to now, high-valent ion conduction is still under debate, given that there are only few works on this field and the direct verification is challenging. With respect to the promising applications of such materials, in aluminium-ion batteries, however, this topic is starting to get into focus [57]. 

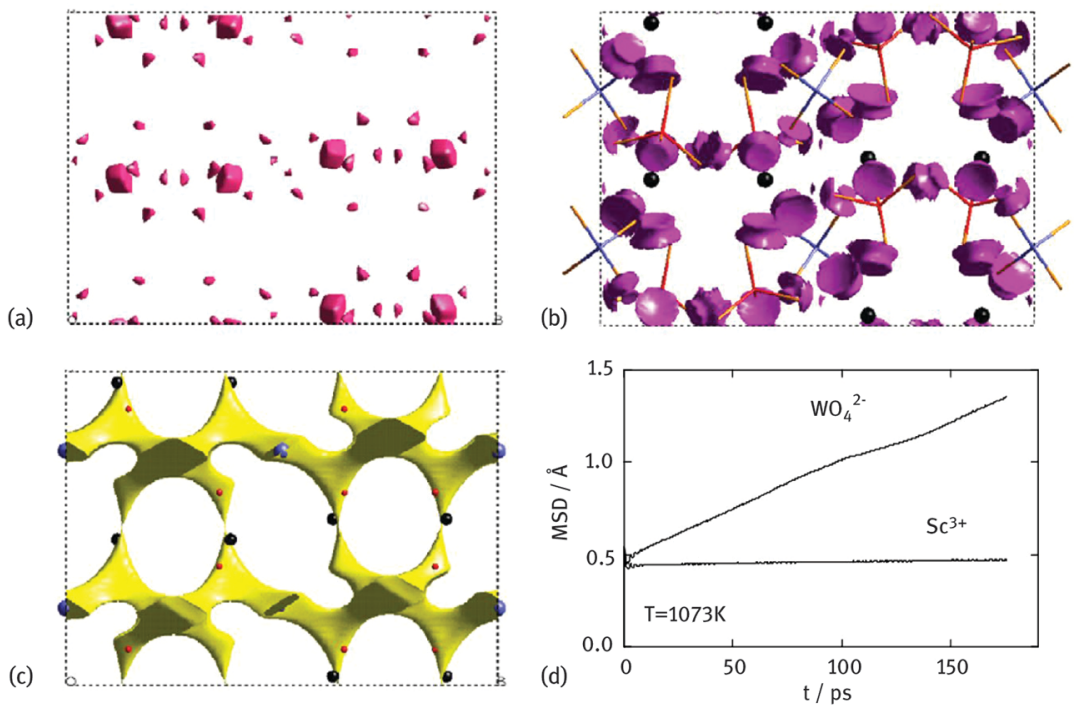

Figure 6: Isosurfaces for a bond valence mismatch of 0.35 valence units for (a) $\mathrm{Sc}^{3+}$, (b) $\mathrm{O}^{2-}$ and (c) $\mathrm{WO}_{4}{ }^{2-}$ in $\mathrm{Sc}_{2}\left(\mathrm{WO}_{4}\right)_{3}$. These isosurfaces can be interpreted as showing the potentially accessible sites and pathways for the respective ion. (d) The mean squared displacement of $\mathrm{WO}_{4}{ }^{2-}$ in a molecular dynamics simulation of $\mathrm{Sc}_{2}\left(\mathrm{WO}_{4}\right)_{3}$ confirms its mobility, in contrast to $\mathrm{Sc}^{3+}$ ions. Reprinted from Solid State Ionics, Stefan Adams, From bond valence maps to energy landscapes for mobile ions in ion-conducting solids, 1625-1630, Copyright (2006), with permission from Elsevier.

To sum up, for superionic transport, there must be a multitude of energetic similar and spatially close sites, which show a low occupancy of the considered mobile ionic species and smooth pathways in between. Despite the structural aspects of the bulk material, the performance of batteries with solid electrolytes will be even more determined by the stability and ion transport properties of the electrolyte/electrode interface [101-105]. Therefore, the next section will focus on this aspect of solid conductors, which has been only marginally considered for a long time.

\subsection{The solid electrolyte - electrode interface}

As already mentioned in the introduction, introducing ceramic particles to polymer-based separators leads to a significant improvement of their properties. Such composite separators or ceramic enhanced separators effectively prevent short circuit and enable fast heat dissipation and tolerance of overcharge. Nevertheless, the presence of polymers in the composites limits the operating temperature range due to their comparatively low melting points. Other drawbacks include their often limited oxidative stability, etc. In this regard, solid electrolytes are preferable as they have high mechanical strength and excellent thermal stability and some of them have also high electrochemical and chemical stability when contacted with electrode materials, including metallic Li or Li-based anode electrode materials and high-voltage electrodes for Li batteries.

Despite their evident advantages, the application of solid electrolytes for electrochemical energy storage devices is difficult. For instance, the properties of an ideal single-crystalline separator will depend on the orientation of the crystallographic direction relative to the direction of the electric field. Real solid materials consist of randomly oriented grains with different types of faces having different specific surface properties and surface area. Therefore, one must be aware that the properties of each particular solid material are determined by the statistical average properties of the ensemble of individual grains. In first approximation, a so-called brick-wall model, it can be proposed that all grains in the material have the same surface type, shape and surface area.

Let us first consider the case of a single-phase solid-state separator in contact with the crystalline electrode (second phase) of the electrochemical device. Then several possible situations can occur (Figure 7):

a. If the adhesion between the phases is poor, then the solid electrolyte/electrode interface comprises an ensemble of point contacts with a small total contact area diminishing over time. In this case, the exchange current is small and such electrodes cannot provide high and stable current densities, despite a high ionic conductivity of the solid electrolyte.

b. If the adhesion between the phases is strong enough, an epitaxial contact layer forms at the interface. The properties of the interface layer depend on the type of the solid electrolyte surface that is in contact with the electrode, relative orientation of the grains and the misfit between the lattice parameters of the phases. 
c. When the adhesion between the phases is very strong, a chemical interaction may take place, resulting in the formation of interface phases. This situation can be observed for example for Li metal electrodes in contact with organic solvents where a so-called SEI forms [106], which covers the surface of the Li anode and prevents it from further reaction with the organic solution. However, such interfaces may only have low ionic conductivity.

(a)

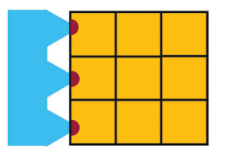

(b)

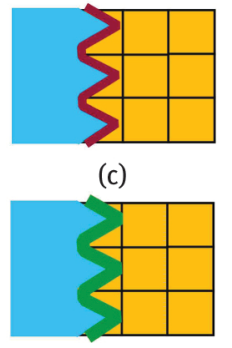

Solid

Electrolyte

Figure 7: Scheme of the electrode/electrolyte interface (red) in the case of (a) poor contact, (b) good contact and (c) the formation of an insulating phase (green) at the interface.

In the optimal case (b), the most stable contact can be found, when no insulating layer forms between the phases. However, even in this case, both the electrolyte/electrode contact and the formed interface layer may be easily broken on cycling due to a strong volume change of the electrode material resulting from the electrochemical processes. Freshly formed cracks act as potential sources of dendrite growth on metallic anodes of batteries. An example of such behaviour is the Na-beta-alumina membrane for Na-S batteries with molten $\mathrm{Na}$ and liquid sodium polysulphides electrodes. These batteries suffer from dendrite formation and their penetration through the solid electrolyte membrane. Similar processes are observed in Li batteries [107]. Another problem of solid electrolytes having high ionic conductivities often is a rather high grain resistance. The reason of this effect is the existence of the surface potential, which can cause an electric double layer that is depleted of the respective charge carriers. For example, the formation of a subsurface so-called diffuse layer depleted of anionic vacancies is responsible for the high grain resistance of oxygen-ion conductivity in zirconia-based solid electrolytes [108-110]. It has been demonstrated that the surface potential in ionic compounds is determined by the adsorption energies of the dominant defects $\left(V_{\mathrm{O}}^{\bullet \bullet}\right)$ and the segregation energy of the dopant ions $\left(\mathrm{Y}_{\mathrm{Zr}}{ }^{\prime}\right)[111$, 112]. Both may be estimated by the Stern model in combination with the Gouy-Chapman and Mott-Schottky models for calculating the potential and concentration distributions in the diffuse layer.

As already mentioned, one main approach for the development of solid electrolytes is to choose a basic compound with suitable crystal structure and doping this compound with different, usually heterovalent, dopants. As a result, the conductivity may be increased at some optimal concentration of defects. However, the dopants can easily segregate at the grain boundaries leading to an increased grain resistance. At present, the question remains open how to control the dopant segregation effect in solid electrolyte ceramics. Doping in high concentrations may cause the formation of impurity phases at grain boundaries that are another reason of the degradation of solid electrolytes. In order to obtain samples with negligible contributions of grain boundaries, one should obtain dense ceramics with large grain sizes. For example, dense conducting ceramics of solid oxygen-conducting electrolytes can be obtained only after prolonged sintering at temperatures not lower than $1,400-1,500^{\circ} \mathrm{C}$. However, sintering of Li-ion conducting ceramics based on compounds with LISI$\mathrm{CON}$, perovskite or garnet-type structure is accompanied by partial evaporation of Li oxide. This causes serious problems with the control of the chemical and phase composition. Hence, the preparation of solid electrolyte with high ionic conductivity and low grain boundaries resistance represents a challenging task.

Alternative materials for separators in batteries are composite solid electrolytes. As opposed to superionic solid electrolytes, in composite solid electrolytes heterogeneous additives produce many interfaces, which enable enhanced conductivity of all non-superionic ionic compounds. A schematic representation of superionic ceramic materials, polycrystalline salts and composite solid electrolytes is presented in Figure 8.

The increased ionic conductivity can be explained by the space charge model proposed by Wagner and Maier [113, 114]. Accordingly, chemical adsorption of ions occurs at the surface of the heterogeneous component, leading to the formation of a dense adsorption layer at the interface and a diffuse layer of vacancies near the interface. This process can be described by the Stern model. Consequently, the conductivity of composites increases as the size of dopant particles decreases. Hence, composites with nanosized grains (about $10 \mathrm{~nm}$ ) 
are of particular interest for practical applications. Adding such oxides to the ionic component may produce a nanocomposite with properties that strongly depend on the character of the interface interaction between the phases. For composites with coarse-grained additives, the presence of interfaces has no appreciable effect on the bulk structural or thermodynamic properties of the ionic salt. In nanocomposites, the salt may transform to a thermodynamically metastable (usually amorphous) phase, which is stabilized by the interface interaction. The concentration and the effective thickness of this phase can be estimated from the dependence of the phase transition enthalpy on the volume fraction of the additive. At a sufficiently high concentration of the additive, the ionic salt may completely transform to a new disordered phase [115].

Today, many composite solid electrolytes are known. Due to their high ionic conductivity, solid electrolytes of the oxide salt type attract great interest especially for the application in batteries and other electrochemical devices. The combination of high conductivity with enhanced mechanical strength, the absence of grain resistance and excellent manufacturability make these composites promising materials for commercial applications. For example, composite solid electrolytes based on LiI have been used in solid-state Li batteries for pacemakers

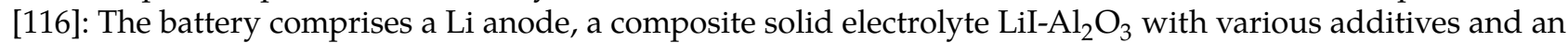
iodine cathode. This primary battery provides a voltage of (2-2.8) $\mathrm{V}$ depending on the anode material, with the specific energy of the battery being in the range of $(150-250) \mathrm{mWh} / \mathrm{g}$. These batteries are characterized by durability with a shelf life of more than 20 years without significant self-discharge and high reliability [117]. The high reliability of solid-state Li batteries is evidenced by the fact that from 1972 to 2000, the Catalyst Research Corporation has produced 150,000 batteries for pacemakers, and none of the batteries failed during these 17 years. The only drawback of such batteries is a small current density.

(a)

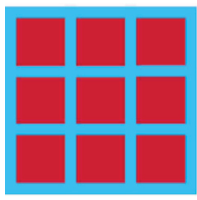

Superionic ceramics (b)

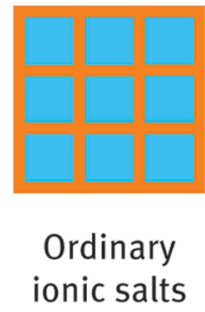

(c)

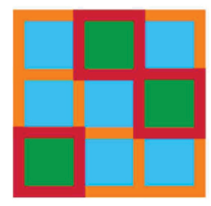

Composite solid electrolytes (d)

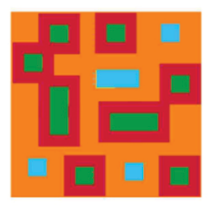

Nanocomposite solid electrolytes

Figure 8: Comparison of superionic ceramics, ordinary salts and composite solid electrolytes. Red areas relate to regions with a high concentration of defects and high ionic conductivity, regions coloured in orange have moderate conductivity, blue areas correspond to regions with low ionic conductivity and particles of the insulating additive are coloured in green.

The use of composite solid electrolytes opens ways to avoid the problem of dendrite growth as the mechanical strains in the composite and nanocomposite materials easily relax due to their effective redistribution along the composite matrix. As a result, the material is much more stable against deformation and does not crack during the electrochemical charge-discharge cycling. A significant advantage of composite solid electrolytes is the possibility to enlarge the electrochemically active electrolyte/electrode area by several orders of magnitude, leading to a strong enhancement of the working current of the device. This requires a special morphology of the composite and the solid electrolyte/electrode intermediate layer.

The morphology of the composites exerts a great influence on their electrical properties. For the description of the conductivity of the common composites of the 'conductor-insulator' type, a mixing equation was proposed [118]:

$$
\sigma^{\alpha}=(1-f) \sigma_{\mathrm{MX}}^{\alpha}+f \sigma_{\mathrm{A}^{\prime}}^{\alpha}
$$

where $\sigma_{\mathrm{MX}}$ is the conductivity of ionic conductor $\mathrm{MX} ; \sigma_{\mathrm{A}}$ is the conductivity of the insulating heterogeneous additive $\mathrm{A}$; and $f$ is the volume fraction of the additive. In traditional mixing rules, the parameter $\alpha$ is taken constant: $\alpha=1$ and -1 for oriented composites consisting of parallel layers of the components when the conductivity is measured in parallel and perpendicular directions, respectively; $\alpha=0$ and $1 / 3$ correspond to the Lichtenecker and Landau-Lifshitz equations, respectively. The analysis shows that the parameter $\alpha$ is determined by the composite morphology and may vary with the concentration [118]. It was assumed that $\alpha$ can be approximated by a linear dependence

$$
\alpha=(1-f) \alpha_{1}+f \alpha_{2},
$$

where $\alpha_{1}$ and $\alpha_{2}$ are determined by the morphology of the composites in the diluted limit $f \rightarrow 0$ and $f \rightarrow 1$, respectively. The mixing equation may be also used for estimating the dielectric permittivity $\varepsilon$ of composites

$$
\varepsilon=\operatorname{Re}\left(\varepsilon^{*}\right)=\frac{\operatorname{Im}\left(\sigma^{*}\right)}{\omega \varepsilon_{0}},
$$


where $\operatorname{Re}\left(\varepsilon^{*}\right)$ and $\operatorname{Im}\left(\sigma^{*}\right)$ are the real part of the complex dielectric permittivity and imaginary part of complex conductivity, respectively; $\omega$ is the angular frequency of the alternating electric field and $\varepsilon_{0}$ is the dielectric constant of vacuum. The generalized mixing rule with the concentration-dependent parameter $\alpha$ provides a satisfactory description of the percolation-type behaviour. In particular, for the ensemble of randomly distributed isolated spherical particles of one component embedded in the matrix of another component $\alpha_{1}=2 / 3$ and $\alpha_{2}=-1 / 3$. In this case, the dielectric permittivity measured at low frequencies goes through a maximum corresponding to the percolation threshold.

For composite solid electrolytes, the mixing rule may be represented in the following form:

$$
\sigma^{\alpha}=\left(1-f-f_{\mathrm{S}}\right) \sigma_{\mathrm{MX}}^{\alpha}+f_{\mathrm{S}} \sigma_{\mathrm{S}}^{\alpha}+f \sigma_{\mathrm{A}}^{\alpha} \quad\left(f_{\mathrm{S}}<f\right),
$$

where $f_{\mathrm{S}}$ and $\sigma_{\mathrm{S}}$ are the total concentration (volume fraction) and the conductivity of the interfacial regions, respectively. The parameter $\alpha(f)$ depends on the concentration as mentioned above. As seen from this equation, additional contribution of the surface to the overall conductivity of the composite is determined by the second term. The conductivity of the interface regions depends on the interface interaction between the components and the concentration of the interfacial regions, which is determined by the morphology of the composite.

For statistically distributed grains of both components, the $f_{\mathrm{S}}$ value can be estimated to be [118]

$$
f_{\mathrm{S}}=\frac{2 \beta \lambda}{L_{\mathrm{A}}} f(1-f)
$$

where $\beta$ is the geometric factor ( $\beta=3$ for cubic particles); $\lambda$ is the thickness of the interface layer and $L_{\mathrm{A}}$ is the particle size of the heterogeneous additive. If $\sigma_{\mathrm{S}}>\sigma_{\mathrm{MX}}$, one should observe a conductivity maximum for a specific volume fraction (Figure 9), which is dependent on the particular values of the parameters $\sigma_{\mathrm{MX}}, \alpha(f), f_{\mathrm{S}}$ and $\sigma_{\mathrm{S}}$. Simultaneously, a dielectric permittivity maximum is observed at the concentration corresponding to the percolation threshold.
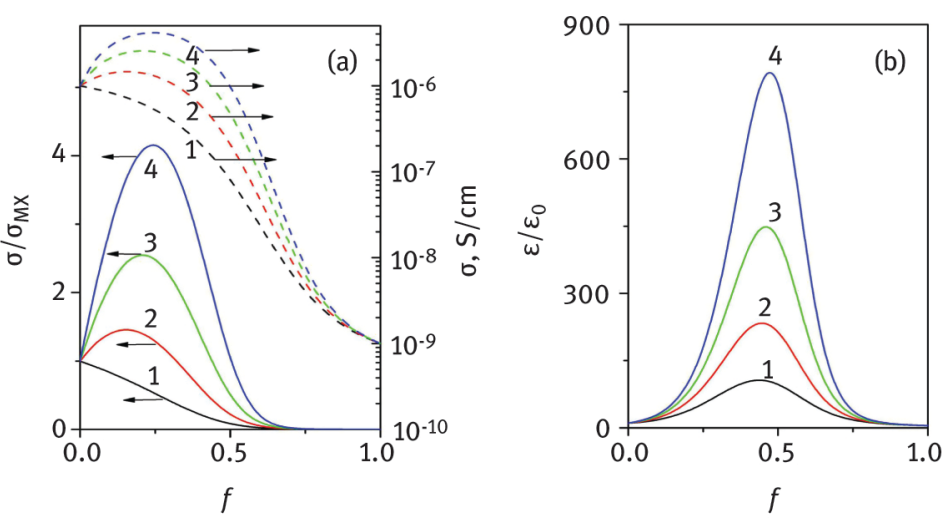

Figure 9: Theoretical dependence of (a) the dc conductivity and (b) low-frequency dielectric permittivity on the volume fraction of the additive for a composite with $\sigma_{\mathrm{MX}}=1 \cdot 10^{-6} \mathrm{~S} / \mathrm{cm}, \sigma_{\mathrm{A}}=1 \cdot 10^{-9} \mathrm{~S} / \mathrm{cm}, \sigma_{\mathrm{S}}=1 \cdot 10^{-5} \mathrm{~S} / \mathrm{cm}$ and $\beta=3$. The ratio $\lambda / L$ varies between $0,0.0167,0.0333$ and 0.05 for the curves $1,2,3$ and 4 , respectively, with $\alpha_{1}=0.667$ and $\alpha_{2}=-0.3337$. The conductivity data in (a) are represented in linear (solid lines) and logarithmic (dashed lines) scales.

Composites with another type of morphology form when the heterogeneous component penetrates the material in a way that it spreads along the space between the grain boundaries and forms a so-called nonautonomous interface phase, which is stabilized by the interface interaction [119]. As the volume fraction of space between the grain boundaries (equal to $f_{\mathrm{S}}$ ) is small, all grain boundaries get filled at low concentrations of the additive. On further increase of the volume fraction, the spreading process stops and the composite behaves as an ordinary statistical mixture. An example of such systems are $\mathrm{MeWO}_{4}-\mathrm{WO}_{3}$ composites, where $\mathrm{Me}=\mathrm{Ca}$, Sr and $\mathrm{Ba}$ [120-122], in which $\mathrm{MeWO}_{4}$ are typical dielectrics and $\mathrm{WO}_{3}$ is a good electronic conductor without any contribution of ionic conductivity. Adding low concentrations of $\mathrm{WO}_{3}\left(f<f_{\mathrm{S}}\right)$ leads to a sharp increase in the ionic conductivity by three or four orders of magnitude. As a result, composite solid electrolytes are formed out of individual components that have no appreciable ionic conductivity. At higher concentrations of $\mathrm{WO}_{3}$, the concentration dependence of the conductivity is typical for composites of the insulator-conductor type and the character of the conductivity changes from ionic to electronic.

Composites formed by filling porous matrixes with ionic salts have a specific morphology and can also be used as solid electrolytes. The pore size distribution and the pore volume are key morphological parameters defining the properties of the matrix. If the pore size is less then (1-3) nm and the adhesion between MX and the surface of $\mathrm{A}$ is sufficiently high, the ionic salt penetrates into the pores and its transport properties 
drastically change [115]. Hence, the part of the ionic salt located inside pores may be regarded as the surface high-conducting phase and its volume fraction is equal to $f_{\mathrm{S}}$. An estimation shows that the dependence of conductivity of such composites on the volume fraction of the porous matrix has a maximum at $f=f_{\max }$, where $f_{\max }$ is the volume fraction of the pores [119]. The mixing equation may be adopted to predict the conductivity and dielectric properties of ternary composites of the conductor-electrolyte-dielectric type [123]. In this case, the equation may be expressed in a more general form

$$
\sigma^{\sum_{i}^{N} \alpha_{\mathrm{i}} f_{\mathrm{i}}}=\sum_{i}^{N}\left(\sum_{\sum_{\mathrm{i}}^{i} \alpha_{\mathrm{i}} f_{\mathrm{i}}} f_{\mathrm{i}}\right),
$$

where $\sigma_{\mathrm{i}}$ and $f_{\mathrm{i}}$ are the conductivity and volume fraction of the ith phase; the parameters $\alpha_{\mathrm{i}}$ have the same meaning as in eq. (7) and the summation is made over all the components of the $N$-phase composite (for a ternary system $N=3$ ). It was shown that in ternary composites the choice of the parameters $\alpha_{\mathrm{i}}$ is ambiguous and possible solutions to this problem have been proposed. In three-phase composites, three percolation thresholds may occur. Their positions, as lines on the ternary plots, may be determined by the dielectric permittivity maxima. The absolute values of permittivity in the maximum, in turn, is determined by the ratio of the conductivities of insulating and conducting phases.

Varying the concentration of the components and the morphology also opens wide possibilities for the improvement of the solid electrolyte/electrode contact. In particular, for the increase of the contact area, one may introduce an additional transient layer containing the electrode material as third phase. The conductivity of such composites can be estimated using a mixing equation for three-phase composite as well. All three phases will play a specific role. The ionic salt enables ionic transport, the additive of the electrode material phase will provide electronic transport to the interfaces and the dispersed insulating phase will serve as both the reinforcing matrix responsible for total integrity of the composite and the heterogeneous dopant generating ion-conducting interfaces. For instance, this idea was employed for the preparation of the composite electrodeelectrolyte interlayer in solid-state supercapacitors [124].

\subsection{Research highlight: $\mathbf{M g}^{2+}$ solid electrolytes for all-solid-state batteries}

Magnesium batteries are one of the most promising candidates for post-Li-ion battery technologies [125]. Mg is a divalent ion and can consequently store two electrons per ion, which translates to a higher volumetric energy density of $3,833 \mathrm{mAh} / \mathrm{cm}^{3}$ compared to $2,036 \mathrm{Ah} / \mathrm{cm}^{3}$ for $\mathrm{Li}$. In contrast to $\mathrm{Li}, \mathrm{Mg}$ can be electroplated without forming dendrites, which can cause short circuits and battery failure [126]. $\mathrm{Mg}$ is also safer than $\mathrm{Li}$ when exposed to air and has a higher natural abundance in the earth crust, making it an excellent candidate for battery anodes. Rechargeable Mg batteries were invented in the early 2000s and have received significant attention since then [127-129]. However, big challenges remain in their development and many aspects of the underlying battery processes at the electrodes, electrolytes and their interface are still poorly understood.

The $\mathrm{Mg}^{2+}$ ion is characterized by a very high charge density, owing to the divalent positive charge carried and the small ionic radius of only $72 \mathrm{pm}$ (Figure 10) [89]. This hampers the mobility of $\mathrm{Mg}$ in the electrolyte and in the cathode host materials, due to the greater electrostatic interaction, compared with monovalent cations such as $\mathrm{Na}^{+}$and $\mathrm{Li}^{+}$. A wide range of intercalation cathode materials and the mechanisms of high-valent ion insertion and migration in those was recently reviewed and numerous studies on liquid Mg electrolytes are available [130-132]. As discussed in the previous section, solid-state batteries offer many advantages over batteries with liquid organic electrolytes. This research highlight will focus on the challenge of finding solid-state electrolyte materials with sufficiently high magnesium-ion conductivity for $\mathrm{Mg}$ batteries.

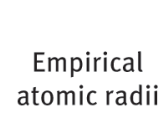

$$
\text { [pm] }
$$

Effective
ionic radi [pm]

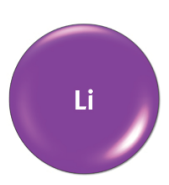

145

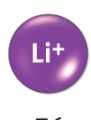

76

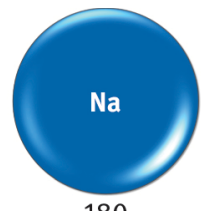

180

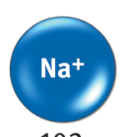

102
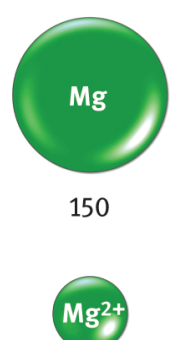

72

Figure 10: Comparison of empirical ionic radii and effective ionic radii for $\mathrm{Li}, \mathrm{Na}$ and $\mathrm{Mg}$ (data taken from [89]). 
Mg-ion conductivity in inorganic solids is rare, but was reported for double-magnesium zirconium orthophosphate, $\mathrm{MgZr}_{4}\left(\mathrm{PO}_{4}\right)_{6}$ [133]. These polycrystalline solid $\mathrm{Mg}$ conductors reach conductivities higher than $10^{-5} \mathrm{~S} / \mathrm{cm}$ at temperatures above $400^{\circ} \mathrm{C}$, and their structure and properties were studied, especially in relation to their potential application as active materials in gas sensors [133-137]. However, in order for a solid-state ionic conductor to be a useful solid electrolyte for battery applications, the ionic conductivity should ideally be close to $10^{-3} \mathrm{~S} / \mathrm{cm}$ at the operating temperature, in order to allow for current densities and thereby charge and discharge rates comparable to those of Li-ion batteries [138]. Polymer-electrolyte systems, typically based on poly(ethylene oxide) (PEO) and $\mathrm{Mg}$ salts, were considered as solid-state electrolytes, but the initially investigated salts $\mathrm{Mg}\left(\mathrm{SO}_{3} \mathrm{CF}_{3}\right)_{2}$ or $\mathrm{Mg}\left(\mathrm{N}\left(\mathrm{SO}_{2} \mathrm{CF}_{3}\right)_{2}\right)_{2}$ are known to form an insulating interphase with the $\mathrm{Mg}$ metal anode [139]. Reversible $\mathrm{Mg}$ plating/stripping was demonstrated for $\mathrm{PEO} / \mathrm{Mg}\left(\mathrm{BH}_{4]}\right)_{2}$ composites [140], and D. Aurbach and coworkers realized a rechargeable solid-state $\mathrm{Mg}$ battery with $\mathrm{PVDF} / \mathrm{Mg}\left(\mathrm{AlCl}_{2} \mathrm{EtBu}\right)_{2}$ / tetraglyme as gel electrolyte, $\mathrm{Mo}_{61} \mathrm{~S}_{8}$ cathode, and $\mathrm{AZ}-31$ magnesium alloy $\left(3 \% \mathrm{Al}\right.$ and $1 \% \mathrm{Zn}$ ) as the anode material. Chevrel phase $\mathrm{Mo}_{6} \mathrm{~S}_{8}$ can intercalate $\mathrm{Mg}$ reversibly at a potential of about $1.2 \mathrm{~V}$ and is often used as a benchmark cathode material, despite its low capacity, for the lack of other intercalation cathodes.

Magnesium borohydride $\mathrm{Mg}\left(\mathrm{BH}_{4}\right)_{2}$ and derived materials were successfully used in liquid electrolytes, thanks to the reductive stability of the $\mathrm{BH}_{4}{ }^{-}$anion. Furthermore, they are also attractive as solid-state $\mathrm{Mg}$ ion conductors [141, 142]. However, the conductivity of pristine $\mathrm{Mg}\left(\mathrm{BH}_{4}\right)_{2}$ in the solid state is extremely low $\left(<10^{-12} \mathrm{~S} / \mathrm{cm}\right.$ at $\left.30^{\circ} \mathrm{C}\right)$ which has been attributed to its structure, in which the $\mathrm{Mg}$ ions are located in firm tetrahedral cages composed of four $\mathrm{BH}_{4}^{-}$units [143]. Higher ionic conductivity of $1 \cdot 10^{-6} \mathrm{~S} / \mathrm{cm}$ at $150^{\circ} \mathrm{C}$ and $\mathrm{Mg}$ plating/stripping was demonstrated for $\mathrm{Mg}\left(\mathrm{BH}_{4}\right)\left(\mathrm{NH}_{2}\right)$ [144], in which $\mathrm{Mg}^{2+}$ is tetrahedrally coordinated by two $\mathrm{BH}_{4}{ }^{-}$and two $\mathrm{NH}_{2}{ }^{-}$groups. Building on the experience that the $\mathrm{Mg}$ ion conductivity can be improved by breaking the strict coordination of $\mathrm{Mg}$ by the $\mathrm{BH}_{4}$ ligands, this concept was extended to complexes of $\mathrm{Mg}\left(\mathrm{BH}_{4}\right)_{2}$ with organic ligands [145]. Ethylenediamine $\left(\mathrm{NH}_{2} \mathrm{CH}_{2]} \mathrm{CH}_{2} \mathrm{NH}_{2}\right.$, abbreviated as en) is a bidentate amine ligand, which coordinates to the metal centre via the lone pairs on the two nitrogen atoms. When reacted in excess with $\mathrm{Mg}\left(\mathrm{BH}_{4}\right)_{2}$, it forms a $\mathrm{Mg}(\mathrm{en}) 3\left(\mathrm{BH}_{4}\right)_{2}$ complex, in which $\mathrm{Mg}$ is octahedrally coordinated by three ethylenediamine ligands and $\mathrm{BH}_{4-}$ act as a counterions [146]. The material crystallizes in an orthorhombic structure and does not show high $\mathrm{Mg}$ conductivity. Only by reducing the number of ethylenediamine ligands per $\mathrm{Mg}$ atom, a mixed coordination of $\mathrm{Mg}$ with ethylenediamine and $\mathrm{BH}_{4}$ is achieved, which leads to a drastically improved ionic conductivity (Figure 11). The synthesis can be carried out by simple mechanochemical reaction between the solid Mg salt and the liquid ethylenediamine, yielding white solids.

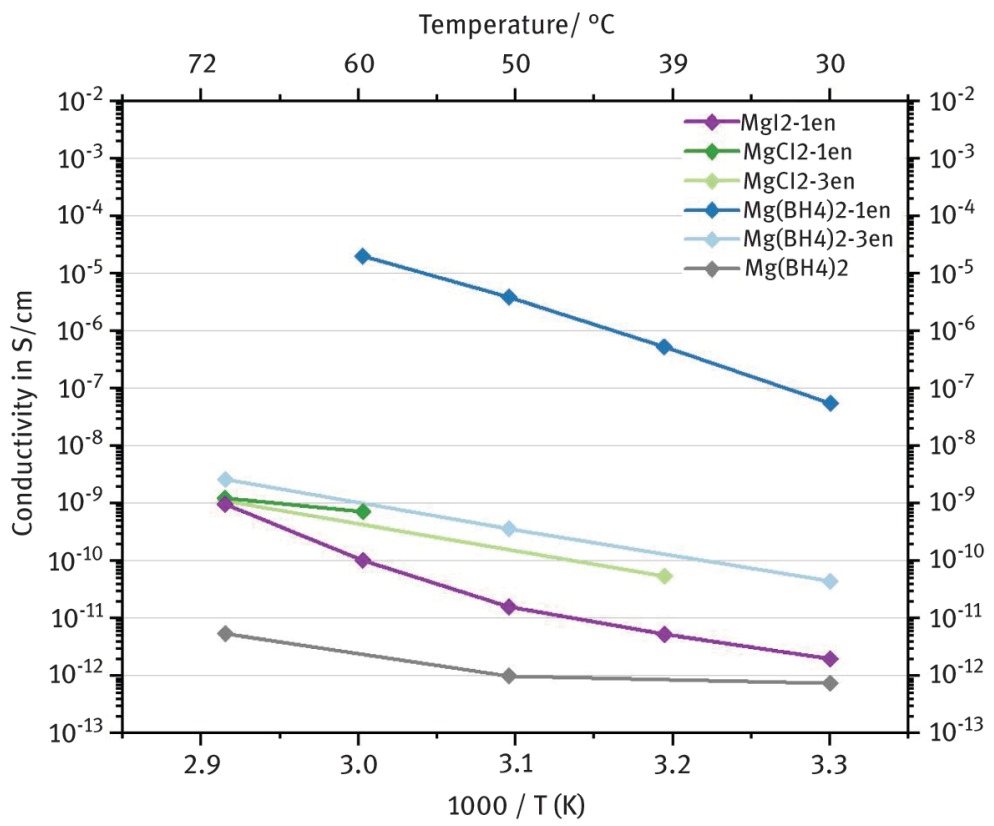

Figure 11: Temperature-dependent ionic conductivity data for $\mathrm{Mg}\left(\mathrm{BH}_{4}\right)_{2}, \mathrm{Mg}\left(\mathrm{BH}_{4}\right)_{2}-3 \mathrm{en}, \mathrm{Mg}\left(\mathrm{BH}_{4}\right)_{2}-1 \mathrm{en}, \mathrm{MgCl}{ }_{2}-3 \mathrm{en}$, $\mathrm{MgCl}_{2}-1 \mathrm{en}, \mathrm{MgI}_{2}$-3en and $\mathrm{MgI}_{2}-1 \mathrm{en}$.

The tetrahedral borohydride anion $\mathrm{BH}_{4}{ }^{-}$is a pseudo-halogenide, whose size $(r=205 \mathrm{pm})$ is in between that of a bromide and iodide ion ( $r=196 \mathrm{pm}$ and $220 \mathrm{pm}$, respectively) [147]. The structures of metal borohydrides are often akin to those of metal halides. Therefore, the ionic conductivity of ethylenediamine-Mg halide complexes was also investigated. However, in this case, the reaction of ethylenediamine with $\mathrm{MgCl}_{2}$ or $\mathrm{MgI}_{2}$ yields products with different structures, lower crystallinity and very low ionic conductivity. The position and num- 
ber of reflections in the obtained powder X-ray diffraction data for $\mathrm{Mg}\left(\mathrm{BH}_{4}\right)_{2}$-1en in Figure 12 indicates a large unit cell and low symmetry of the structure. Combined with the low crystallinity of the samples, this makes structure solution from powder X-ray diffraction data extremely challenging.

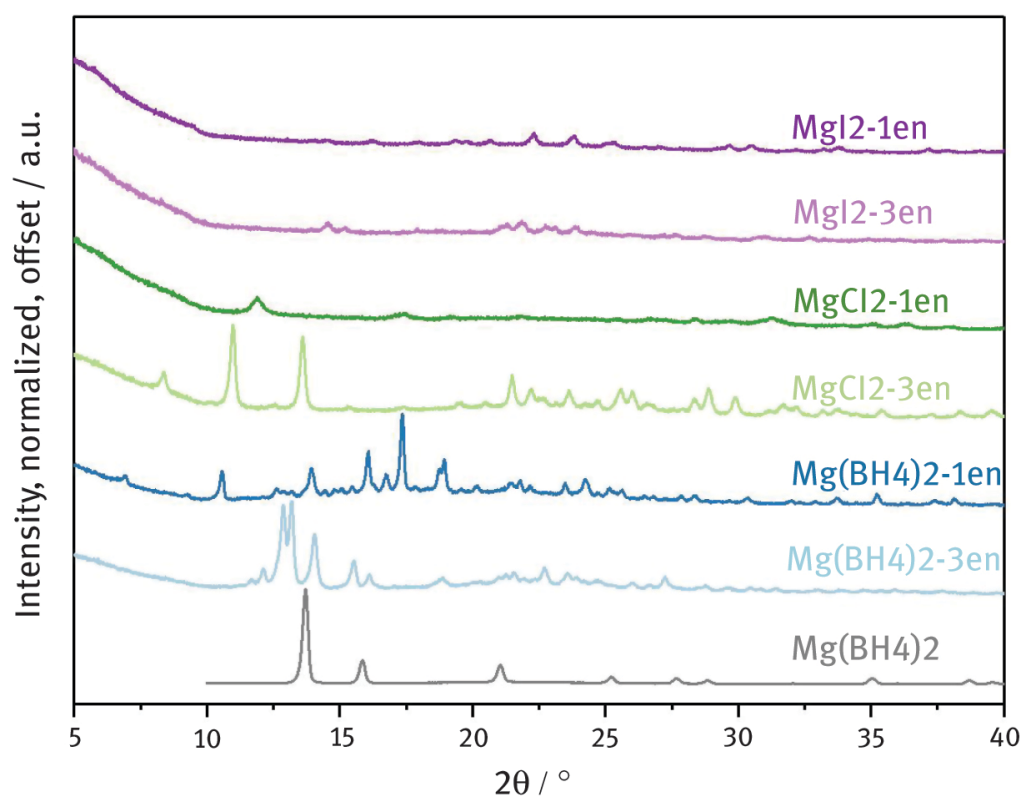

Figure 12: Powder X-ray diffraction data for $\mathrm{Mg}\left(\mathrm{BH}_{4}\right)_{2}, \mathrm{Mg}\left(\mathrm{BH}_{4}\right)_{2}$-3en, $\mathrm{Mg}\left(\mathrm{BH}_{4}\right)_{2}$-1en, $\mathrm{MgCl}_{2}$-3en, $\mathrm{MgCl}_{2}-1$ en, $\mathrm{MgI}_{2}$-3en and $\mathrm{MgI}_{2}-1 \mathrm{en}$.

Typical methods for preparing single crystals for X-ray analysis, such as recrystallization from a solvent, fail in this case, since the solvent molecules coordinate to the essentially under coordinated $\mathrm{Mg}$ ion, and cannot be removed. Vibrational spectroscopy, i.e. FTIR and Raman, can be used to confirm the chelating coordination of ethylenediamine around $\mathrm{Mg}$ in a cis-conformation [145, 148-151], but does not allow drawing conclusions about the long-range order. Without knowing the crystal structure, the mechanism of the ionic conductivity in these materials is yet to be finally understood. The much higher ionic conductivity in $\mathrm{Mg}\left(\mathrm{BH}_{4}\right)_{2}-1$ en compared to $\mathrm{MgCl}_{2}$-1en and $\mathrm{MgI}_{2}-1$ en indicates that the tetrahedral $\mathrm{BH}_{4}{ }^{-}$ion plays an important role for the cation mobility. Borane anions are known to facilitate the passage of mobile species through reorientational movements, a socalled 'paddle-wheel' mechanism [152, 153].

To be used in solid-state batteries, an electrolyte does not only need to allow for high cation mobility, but must also be compatible with the electrode materials, that is $\mathrm{Mg}$ metal and the chosen cathode material. While $\mathrm{Mg}\left(\mathrm{BH}_{4}\right)_{2}$-1en was used successfully as electrolyte for the electrodeposition and stripping of $\mathrm{Mg}$, the oxidative stability of the material is very low and oxidative currents are observed starting at $0.7 \mathrm{~V}$ versus $\mathrm{Mg}$. With this small stability window, the material is not suitable for application in practical batteries. The stability can, however, be tuned by employing other chelating ligands and $\mathrm{BH}_{4}{ }^{-}$could be replaced with different complex anions, such as $\mathrm{BF}_{4}{ }^{-}$. In this way, a large variety of materials are available and currently being studied. This research highlight shines a spotlight on the difficulties of designing solid-state electrolytes for multi-valent ions. Solidstate $\mathrm{Mg}$-ion batteries which can compete with state-of-the-art Li-ion batteries are still a long way in the future and many challenges will have to be overcome. So far, no system shows high enough ionic conductivity, but even more importantly, research must also focus on the electrochemical stability of the investigated materials and the compatibility with anode and cathode. Nonetheless, the promise that solid-state Mg batteries hold in terms of energy density, cost, safety and easy architecture will drive future research.

\subsection{Research highlight: The all-in-one all-solid-state battery}

In recent years, functional transition metal oxides become more and more important as components of electrochemical energy storage devices, especially due to their manifold properties [154]. Besides this intrinsic diversity, they can be significantly tuned by defects. Research topics comprise the usage of oxides in primary or secondary batteries as solid electrolytes in sodium-sulfur batteries [155] or solid oxide fuel cells [156]. Working as host structures for intercalation in Li-ion batteries [157], they have great potential as electrodes in supercapacitors [158] as well as catalysts in metal-air batteries [159]. As a result of their chemical and thermal stability, environmental compatibility, high abundance and low costs, they are suitable for all-solid-state battery con- 
cepts. One opportunity to generate new concepts is the synergy of data and energy storage technologies [160, 161], which are based on migration of sufficient mobile charged defects in an external electric field.
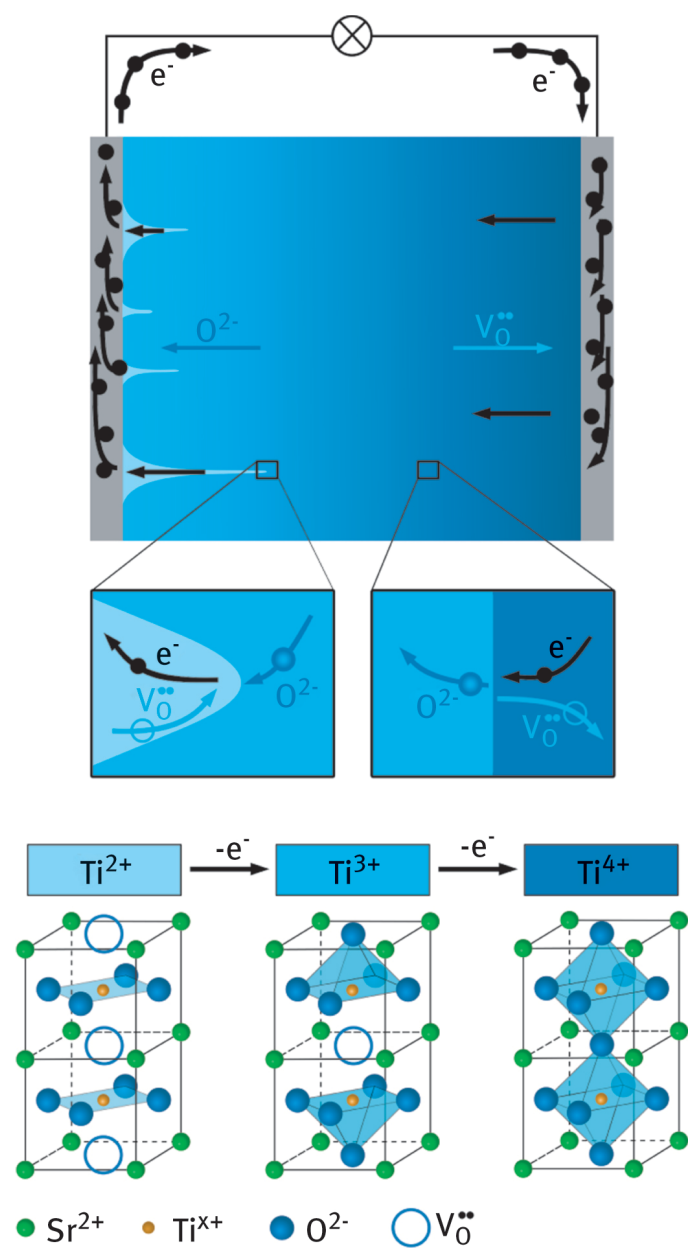

Figure 13: Exergonic discharging process of a $\mathrm{SrTiO}_{3}$ rechargeable battery. The electromotive force is caused by a redistribution of oxygen vacancies during the charging process which leads to an accumulation at the negative electrode and a depletion at the positive electrode. Dendrites, built of $V_{\mathrm{O}}^{\bullet \bullet}$-clusters $\left(\mathrm{Ti}^{2+}\right)$, dissolve into stoichiometric $\mathrm{SrTiO}_{3}\left(\mathrm{Ti}^{4+}\right)$ to form statistically distributed $V_{\mathrm{O}}^{\bullet \bullet}\left(\mathrm{Ti}^{3}\right)$. Drawn after reference [160].

Hence, metal-insulator-metal (MIM) stacks, in particular $\mathrm{Ti}-\mathrm{SrTiO}_{3}-\mathrm{Ti}$, undergo special charge and discharge cycles [160]. Applying an external electric field to the functional oxide is accompanied by redistribution of oxygen vacancies $V_{O}^{\bullet}[162,163]$, because these defects are charged twofold positive (after Kröger-Vink notation [164]). The process is called electroformation or charge process [165-167]. In consequence of $V_{\mathrm{O}}^{\bullet \bullet}$ redistribution and the retention of electroneutrality, the following redox couples arise, which are attributed to the respective electrode:

$$
\begin{aligned}
& \text { Anode: } \mathrm{Ti}^{3+} \rightarrow \mathrm{Ti}^{4+}+\mathrm{e}^{\prime} \\
& \text { Cathode: } \mathrm{Ti}^{3+}+\mathrm{e}^{\prime} \rightarrow \mathrm{Ti}^{2+}
\end{aligned}
$$

Imbalance in the $\mathrm{SrTiO}_{3}$ single crystal caused by defect separation enables an electromotive force which, due to its exergonic character, now drives the discharging process of the electrochemical energy storage, when the electric field is switched off. The exergonic nature of this process was demonstrated by means of density functional theory as well as laws of thermodynamics [160]. The proposed redox mechanism is the oxidation as well as reduction of the Ti cation, which can take three different oxidation states. Therefore, the transition metal oxide not only assumes the function of a solid electrolyte, but also acts as anode and cathode, which means that $\mathrm{SrTiO}_{3}$ serves as all-in-one solid-state battery.

Up to now, a capacity of $3 \mathrm{mAh} / \mathrm{kg}$, which remains constant in several charging/discharging cycles, has been determined [160]. Furthermore, the expected linear dependence of the capacity on the volume of the cell was confirmed [160]. Nevertheless, battery parameters have to be optimized, regarding other established electrochemical energy storage, such as metal-air batteries or Li-ion batteries. Potential research topics could be: 
- usage of transition metal oxides with redox couples, exhibiting a higher difference in their redox potentials, e. g. $\mathrm{Fe}, \mathrm{Mn}$ or $\mathrm{Cr}$, to increase cell voltage

- combination of two different transition metal oxides, establishing a bifunctional redox couple to enhance the cell voltage, which is connected to defect migration across the interphase

- introduction of a higher point defect density to raise capacity

- transfer of macroscopic solid-state battery mechanism to thin films to lower the charge voltage

- optimization of crystal orientations, because the migration of oxygen vacancies is an anisotropic phenomenon [168]

- application of higher temperatures to reduce the charging time since oxygen vacancy migration follows an Arrhenius behaviour [168]

\section{Ionic liquids}

\subsection{Fundamentals}

ILs are molten salts with melting points below $100{ }^{\circ} \mathrm{C}$ [169-172]. They are generally composed of a bulky, asymmetric organic cation and a weakly coordinating inorganic/organic anion. ILs are typically non-flammable, have negligible vapour pressure and display high chemical and thermal stability [171, 172]. Moreover, they can also show high ionic conductivities and wide electrochemical stability windows [171, 172]. Because of these properties, ILs are presently considered one of the most interesting classes of alternative electrolytes for Liion batteries and supercapacitors [173, 174]. Their non-flammability contributes to cell safety, while their nonvolatility, resulting from vapour pressures comparable to metallic $\mathrm{Cd}$ or $\mathrm{Zn}\left(\sim 10^{-13}\right.$ times that of water), enables the use of ILs even in open cells such as Li-air. ILs and their properties can be engineered by changing their structure, so that various important requirements such as high ionic conductivity, interfacial and electrochemical stabilities as well as thermal stability and low flammability can be simultaneously met $[175,176]$. These features allow the realization of safer electrochemical storage devices, be it supercapacitors [177-179], batteries [180-193] and solar cells [194].

In the most conventional ILs employed for electrochemical storage, the typical cation is a quaternary amine or an asymmetrically substituted imidazolium ring with delocalized charge (Figure 14). The typical anion possesses some flexibility and some of its structural moieties are free to rotate around one or more axes. The anion and/or the cation are bulky, so that their charge is screened, and the nucleation process is hindered, leading to their extremely low melting points (compare to the melting point of $\mathrm{NaCl}$ at $804^{\circ} \mathrm{C}$ ). The electrostatic forces between the species in the liquid are more intense than van der Waals forces for similarly sized molecules, so that ILs are generally characterized by elevated viscosity values, typically in the range $30-50 \mathrm{cP}$ at $25{ }^{\circ} \mathrm{C}$ (water: $0.89 \mathrm{CP}$ ) and a negligible vapour pressure [195].

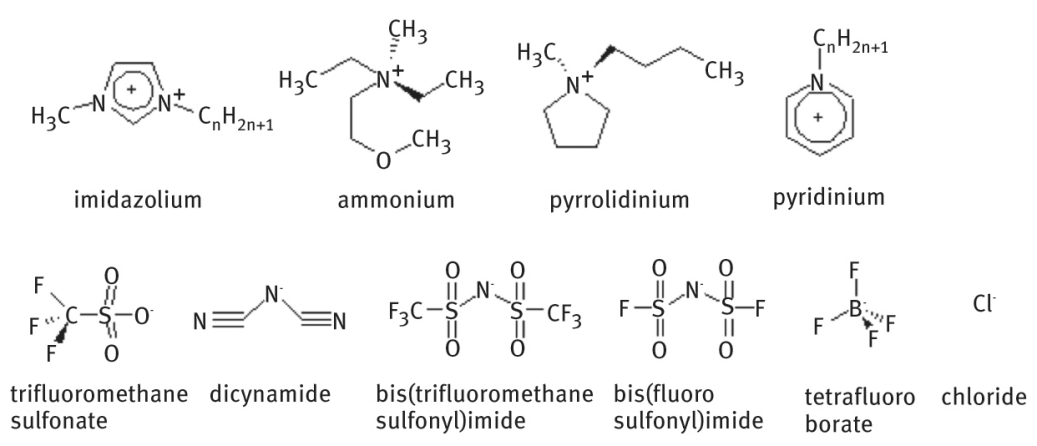

Figure 14: Cations (first row) and anions (second row) typically found in ionic liquids.

The electrostatic nature of ILs also reflects in their ionic conductivity. In a similar fashion to ionic solids, the probability of finding two like-charged species side to side is very low. There are rather three-dimensional patterns of alternating anions and cations across the liquid, whereby the existence of neutral aggregates with the same number of cations and anions cannot be ruled out. Especially below the glass transition temperature, the ions assume a quasi-oriented alignment similar to that in liquid crystals (Figure 15) [197]. The formation of 
ion aggregates reduces the mobility of the ions and thus limits the cell power. Ion transport is not as straightforward as it is in conventional electrolytes, and common mathematical descriptions of transport (derived under simplified conditions) cease to work [198]. Typical conductivities are in the order of $0.118 \mathrm{mS} / \mathrm{cm}$ (compared to aqueous $\mathrm{KOH}$ with $29.4 \mathrm{wt} \%: 540 \mathrm{mS} / \mathrm{cm}$ ) and are strongly affected by the structure of the solvated ions [195]. Because of the reduced ion conductivity, mixtures of conventional solvents with ILs have been proposed, so as to achieve good conductivities while keeping the stability and safety advantages of ILs. That should reduce the price by diluting the more expensive ILs with organic electrolytes, too.
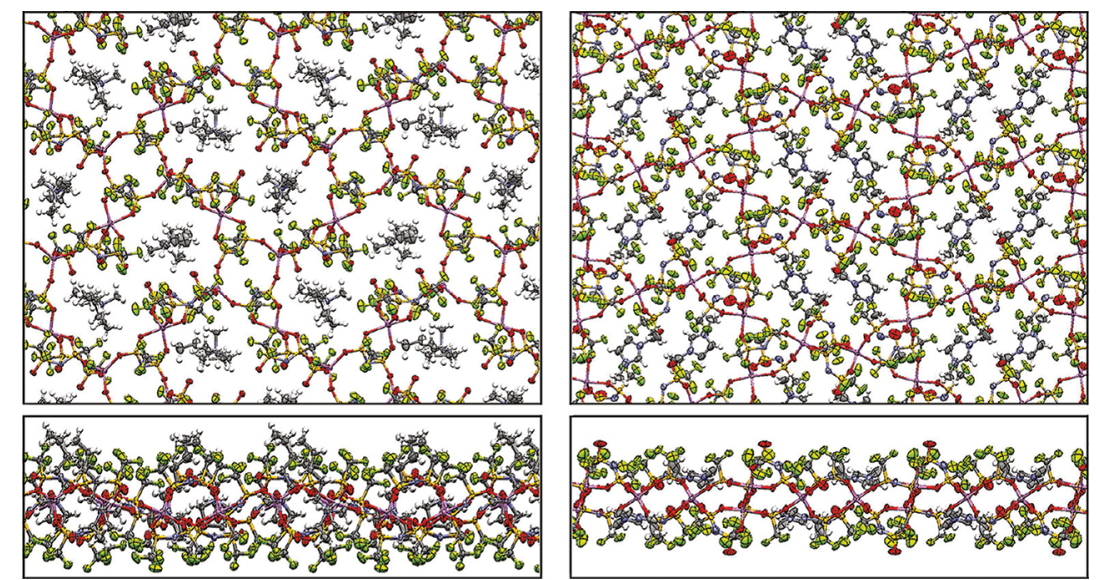

Figure 15: Image of the crystal structure of $(1-x) \operatorname{Pyr}^{15}$ TFSI- $(x)$ LiTFSI $(x=0.67)$ [196] (left image) and of the same crystalline phase rotated by 90 (right-image) (Li: purple; O: red; S: yellow; N: blue; F: green). Reprinted with permission from [197]. Copyright 2011 American Chemical Society.

\subsection{Ionic liquids as electrolytes for Li batteries}

The most attractive property of ILs for Li battery applications is the elevated electrochemical stability of some cation and anion types, which leads to the possibility to develop high-energy-density Li batteries. The key advantages offered by ILs electrolytes are a low volatility and low flammability, reflecting in an enhanced safety and stability of the electrochemical storage system. Some of the earliest reports on the use of ILs as electrolyte for Li battery applications showed a sufficient stability of quaternary ammonium and phosphonium salts [199, 200], generating a great interest in the application of ILs electrolyte in Li batteries. Generally, the cations of roomtemperature ILs (RTILs) are typically nitrogen-based, and one of the most promising ones is imidazolium [201203]. However, it was observed that imidazolium is relatively easy to reduce (its proton positioned at $C 2$ can be reduced at redox potentials higher than that needed for lithiation at the anode). This causes an irreversible decomposition of the RTIL, which results in poor reversibility at the negative electrode for Li-ion batteries.

Quaternary ammonium cations (without acidic proton) display higher cathodic stability than imidazoliumbased RTILs [204]. Further cations including sulfonium and phosphonium have also been investigated for improving the physicochemical and electrochemical properties of RTILs [205-207]. The first developed RTILs included $\mathrm{NO}_{3}{ }^{-}$or $\mathrm{AlX}_{4}{ }^{-}(\mathrm{X}=$ halogen $)$ anions, characterized by elevated chemical instability, high corrosivity and toxicity. The first water- and air-stable RTILs, introduced in 1992, replaced the above-mentioned anions with tetrafluoroborate, $\mathrm{BF}_{4}{ }^{-}$[208]. Although extensively studied, the application of $\mathrm{BF}_{4}{ }^{-}$anion-based RTILs as electrolytes was limited by their serious drawbacks, such as a relatively high melting point and cost. The breakthrough followed the introduction of a new anion, the bis(trifluoromethanesulfonyl)imide (TFSI) by 3M. The use of TFSI in IL electrolyte considerably enhanced the overall physicochemical properties of RTILs, lowering their melting point and viscosity as well as increasing their conductivity. Since then, various ammoniumbased RTILs, combined with TFSI, have been studied [197, 209, 210]. Recently much interest emerged on the bis-(fluorosulfonyl)imide (FSI) anion which has a fluorine atom instead of a $\mathrm{CF}_{3}$ group (in TFSI). First described in 1962 [211], Armand and coworkers patented its use as a plasticizing anion in solid polymer electrolytes [212]. More recently, it has been successfully employed in Li ion systems [213]. Besides the significantly higher conductivity and lower viscosity values, FSI is characterized by a remarkable SEI-forming ability. The FSI- anion can decompose during the reduction process at the alloy anode (S-F bond breaking). This process leads to the formation of $\mathrm{SO}_{2}$ and $\mathrm{LiO}$ at the anode/electrolyte interface and the consolidation of the SEI layer by adherent compounds such as $\mathrm{LiF}, \mathrm{LiO}, \mathrm{LiOH}$ and $\mathrm{Li}_{2} \mathrm{SO}_{4}$ [214]. Figure 16a shows an example of a $\mathrm{Li}$-ion battery prototype obtained employing a $\mathrm{Pyr}_{14}$ FSI-LiTFSI electrolyte, a nanostructured $\mathrm{Sn}-\mathrm{C}$ anode and a $\mathrm{LiFePO}_{4}$ (LFP) cathode. The cell delivers a specific capacity as high as $160 \mathrm{mAh} / \mathrm{g}$ at a lower current of $25 \mathrm{~mA} / \mathrm{g}$ and a still satisfactory 
value of $105 \mathrm{mAh} / \mathrm{g}$ at $250 \mathrm{~mA} / \mathrm{g}$, with a rather remarkable rate capability, cycling trend and coulombic efficiency (Figure 16a, b). The cycling test of the Li-ion cell at the current density of $100 \mathrm{~mA} / \mathrm{g}$ (Figure 16c) reveals a reversible capacity of $150 \mathrm{~mA} / \mathrm{g}$ with negligible capacity fading, a coulombic efficiency higher than $99.9 \%$ resulting in a cycle-life extension of over 1,000 cycles, and an average working voltage change by cycles limited to about $100 \mathrm{mV}$ (Figure 16d). The reported Li-ion cell is indeed extremely appealing as a safe energy storage system, demonstrating the possibility to obtain high-performance Li-ion battery systems employing IL-based electrolytes [213].
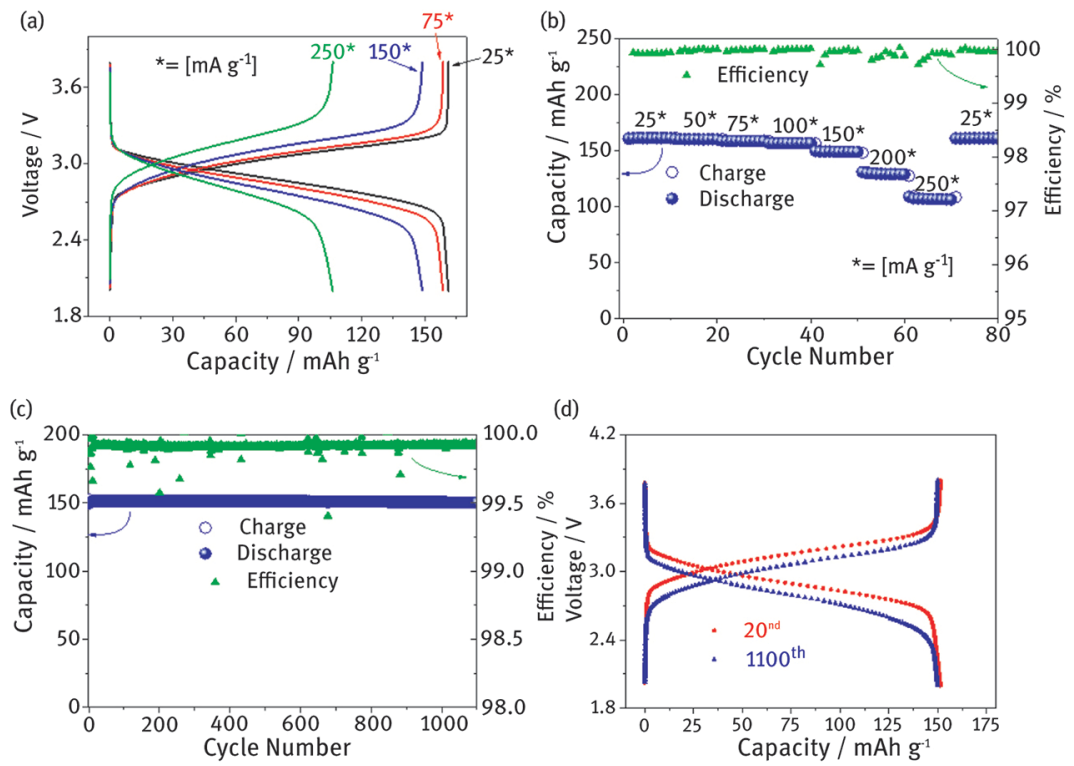

Figure 16: (a) Selected steady state voltage signatures and (b) cycling behaviour with columbic efficiency of the SnC/Pyr ${ }_{14}$ FSI-LiTFSI/LFP cell galvanostatically measured at increasing currents, i. e. 25, 50, 75, 100, 150, 200 and $250 \mathrm{~mA} / \mathrm{g}$ $\left(0.12,0.24,0.36,0.48,0.72,0.96,1.2 \mathrm{~mA} / \mathrm{cm}^{2}\right.$, respectively). (c) Columbic efficiency and (d) steady-state voltage signatures of the Sn-C/Pyr ${ }_{14}$ FSI-LiTFSI/LFP cell upon long-term galvanostatic cycling test at $100 \mathrm{~mA} / \mathrm{g}\left(1.2 \mathrm{~mA} / \mathrm{cm}^{2}\right)$. Reproduced from Ref. [213] with permission from The Royal Society of Chemistry.

\subsection{Ionic liquids as electrolytes for post-Li-Batteries}

The Li-ion technology is the power source of choice in portable electronic devices and for electric vehicle applications. Unfortunately, due to the cost and limited resources of $\mathrm{Li}$, the use of $\mathrm{Li}$-ion batteries for large-scale applications is nowadays under discussion $[215,216]$. The development of electrochemical storage systems employing more abundant metals as anodes (such as sodium [217-221], potassium [222, 223], calcium [224, 225], magnesium $[127,226]$ and aluminium [227-230]) can lead to a reduction of the cost and to long-term sustainability [231, 232]. In this context, IL electrolytes play an important role.

In sodium batteries, both imidazolium- and pyrrolidinium-based ILs have been tested. Interestingly, the effect of Na salt addition on the viscosity and conductivity of ILs is only minor, as opposed to Li, where Li salt addition leads to a remarkable reduction in the ionic conductivity and an increase of the viscosity [233]. As a result, sodium cells employing IL electrolyte show comparable and in some case even superior performances in respect to organic solvents. Also, the performance of several cathode materials in ILs has been shown to be similar to that in organic electrolytes. In the case of layered metal oxides, the performance in ILs is significantly better due to their higher stability in ILs (reduced dissolution of transition metals as Mn) [192], higher reversibility of the cathode phase transition at high potentials as well as corrosion reduction of the $\mathrm{Al}$ current collector [234]. Anode materials such as Sn, Sn-Cu alloys and hard carbon have been successfully tested in ILs. Depending on the chosen IL, stable capacities at both $25^{\circ} \mathrm{C}$ and $90^{\circ} \mathrm{C}$ have been achieved [181]. Figure 17 shows the voltage signature of one of the few complete sodium-ion full cells employing an IL electrolyte, a Sb-C nano composite anode and a $\mathrm{Na}_{0.6} \mathrm{Ni}_{0.22} \mathrm{Fe}_{0.11} \mathrm{Mn}_{0.66 \mathrm{O} 2}$ cathode (most studies test only anode or cathode materials and employ sodium metal as counterelectrode). 

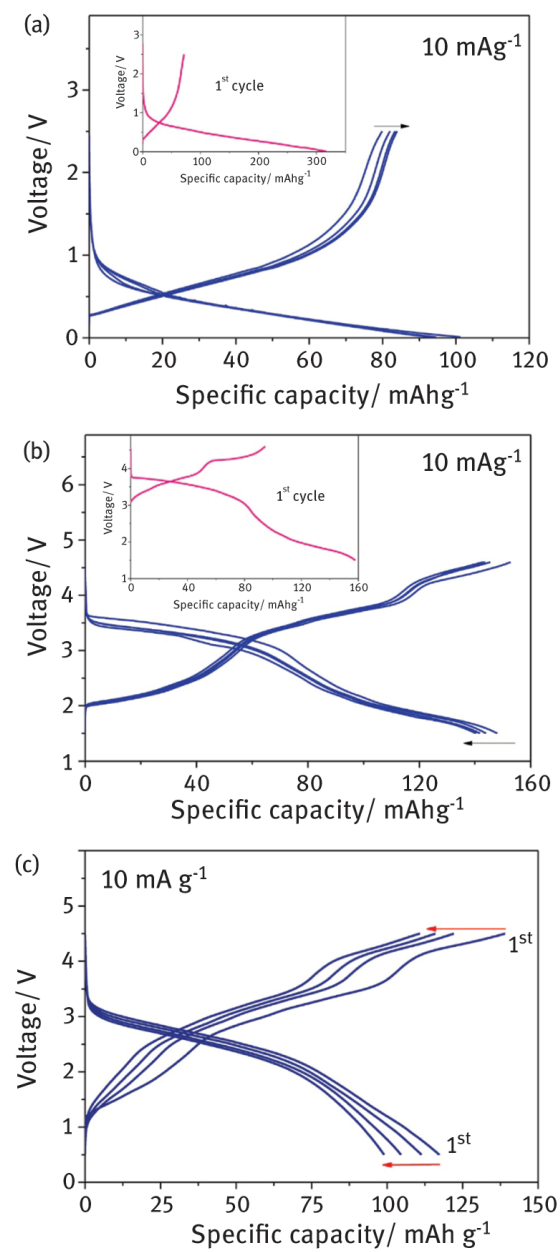

Figure 17: Voltage profile of the $\mathrm{Na}_{\mathrm{x}} \mathrm{Sb}-\mathrm{C} / 0.2 \mathrm{~m} \mathrm{NaTFSI}-\mathrm{Pyr}_{14} \mathrm{TFSI} / \mathrm{Na}_{0.6} \mathrm{Ni}_{0.22} \mathrm{Fe}_{0.11} \mathrm{Mn}_{0.66 \mathrm{O}}$ full cell cycled at $10 \mathrm{~mA} / \mathrm{g}$. Room temperature $\left(25^{\circ} \mathrm{C}\right)$.

In the field of $\mathrm{Mg}$ batteries, IL-based electrolytes have been widely investigated [235]. One of the main issues in the $\mathrm{Mg}$ battery is the elevated corrosivity of the electrolyte employed. A reactive electrolyte is needed to activate the passivated $\mathrm{Mg}$ metal surface, enabling the reversible stripping-deposition process. Thanks to their unique tunability, ILs can be modified according to the specific requirements. For instance, it has been demonstrated that ethers (such as THM) can coordinate Mg ions preferentially over nitrogen ligands without making the solvent too viscous for efficient transport. In addition, they improve the deposition/dissolution properties of $\mathrm{Mg}$ [236]. Watkins [237] successfully introduced ether functionalities into the IL cation evidencing a more convenient binding of $\mathrm{Mg}$ ions which favours deposition over decomposition.

In the field of secondary aluminium batteries, ILs are in fact the most utilized electrolyte media. As evidenced by Kamath et al. [238], the formation of low-stability, ion-solvent complexes in IL-based electrolytes facilitates the rapid Al ion solvation-desolvation, leading to enhanced transport properties compared to, for example, carbonate-based solvents. IL-based electrolytes for application in aluminium batteries are generally composed by a mixture of an IL $\left(\mathrm{M}^{+} \mathrm{X}^{-}\right)$and $\mathrm{AlCl}_{3}$ [239-245], where $\mathrm{M}^{+}$can be an organic cation like pyrrolidinium or imidazolium, while $\mathrm{X}^{-}$can be a halogen anion such as $\mathrm{Cl}^{-}, \mathrm{Br}^{-}$or $\mathrm{I}^{-}$or an organic anion, i. e. the TFSI or trifluoromethanesulfonate. The most investigated ILs for such applications are those based on the imidazolium cation $\left(\mathrm{M}^{+}\right)$bearing different alkyl side chains, such as 1-butyl-3-methylimidazolium (BMIM) or 1-ethyl-3-methylimidazolium (EMIM), while the most used anion ( $\mathrm{X}^{-}$) is chloride [227, 228, 246]. The mole ratio between the IL and $\mathrm{AlCl}_{3}$ is one of the fundamental parameters governing the electrochemical performance of these electrolytic solutions [247-249]. In fact, only in the acidic melt, in which the mole ratio between $\mathrm{AlCl}_{3}$ and $\mathrm{MX}$ is higher than one, is the $\mathrm{Al}_{2} \mathrm{Cl}_{7}{ }^{-}$species present. This anion is considered the fundamental species enabling the reversible stripping-deposition process [250]. One of the main practical issues to address for the realization of cell prototypes is the corrosivity of this class of electrolytes. A compromise between the required lability to enable reversible processes and a not excessive corrosiveness to the other cell components should be found.

While $\mathrm{Zn}$ is widely deployed in primary batteries, interest in exploiting its specific energy density in secondary $\mathrm{Zn}$-air batteries is on the increase. Some problems associated with the electrolyte (concentrated aqueous $\mathrm{KOH})$ are the corrosion of other battery parts, drying-out, dendrite formation and reaction with atmospheric 
$\mathrm{CO}_{2}$. The application of ILs has shown that both the IL anion and cation play a decisive role in the process of zinc deposition. While the anion influences the deposition mechanism (two successive one-electron or a single two-electron step in dicyanamide (DCA) and TFSI respectively), the cation affects the quality, size and overpotential of the deposits through its interaction with the metallic Zn surface [236].

Two approaches are being investigated: the addition of IL to the alkaline electrolyte and the addition of water to an IL electrolyte. In the former case, the addition of even $0.5 \mathrm{wt} \%$ of 1-ethyl-3-methylimidazolium dicyanamide to the aqueous $\mathrm{KOH}$ electrolyte enabled the deposition of non-dendritic Zn clusters [251]. Higher water concentrations can be advantageous or damaging according to the IL system. In the later approach, small amounts of water in DCA improved the fluidity of the IL as well as the morphology of Zn deposits, but concentrations $>10 \%$ water can impede $\mathrm{Zn}$ reoxidation. In TFSI, water reduces the overpotential associated with deposition [236].

\section{Conclusion}

Current organic electrolytes and thin separators in commercial Li-ion battery systems demonstrate crucial safety deficiencies. Furthermore, the urgent need for higher energy densities drives the development of alternative electrolyte chemistries: They are needed as key enabler for next-generation Li batteries as well as high-valent battery systems. Among them, solid electrolytes are promising candidates that have already overcome the hurdle of utilizable ion conductivity, at least in the case of Li batteries. Employing the outlined appropriate structural motifs and framework ions as well as tailored doping may also lead to utilizable mobilities for other ion species. As an example for cell chemistries with other mobile species, current research on magnesium borohydride-based complexes as electrolytes for solid-state $\mathrm{Mg}$-ion batteries has been presented. $\mathrm{Mg}$ batteries offer many advantages over Li batteries, but the high charge density of the $\mathrm{Mg}^{2+}$ ion also poses serious challenges for the search of suitable electrolyte and cathode materials.

Higher conductivities can be also reached by composite solid electrolytes, which can be described by the so-called mixing equation. However, in many cases not the bulk properties of solid electrolytes, but rather the intergrain interfaces and the solid electrolyte-electrode interface dominate the performance. Thus, the main issue is to optimize the electrode-electrolyte interface to provide a low-resistant and durable contact upon cycling.

A concept to bypass the interface problem is the presented all-in-one rechargeable energy storage solely utilizing an oxygen-deficient single crystal of $\mathrm{SrTiO}_{3}$, serving as anode, cathode as well as electrolyte. This work may potentially inspire similar approaches, utilizing a field-induced redistribution of vacancies and defect separation, establishing a non-equilibrium state accompanied by an electromotive force.

Another alternative, offering high safety, while not dealing with the interface problems of solid electrolytes, are ILs. Their tuneable properties, such as high ionic conductivity, low volatility, reduced flammability and high electrochemical and chemical stability offer new possibilities in battery research. At the same time, their current drawbacks, as in the case of Al-ion batteries - high prices and corrosivity against other cell components - need to be solved.

\section{Funding}

$\mathrm{TN}, \mathrm{JH}$, and MdV are grateful for financial support of the Federal Ministry of Education and Research (CryPhysConcept (03EK3029A) and R2RBattery (03SF0542A)). Furthermore, ER thanks the Swiss National Science Foundation for financial support within the Sinergia project 'Novel ionic conductors' (CRSII2_160749/1).

\section{Notes}

1 If there is an additional comparably high electronic conductivity, they are called mixed conductors, which are good candidates for intercalation electrodes but not as separator. 


\section{References}

[1] Nestler T, Schmid R, Münchgesang W, Bazhenov V, Schilm ], Leisegang T, et al. Separators-technology review: ceramic based separators for secondary batteries. In: AIP Conference Proceedings, volume 1597. AIP, 2014: 155-184.

[2] https://electrek.co/2016/08/15/tesla-model-s-catches-fire-test-drive-france/ (2016).

[3] https://www.cnet.com/news/why-is-samsung-galaxy-note-7-exploding-overheating/ (2016).

[4] Volta A. On the Electricity excited by the mere Contact of conducting Substances of different kinds. Philos Trans R Soc 1800;2:403

[5] Washburn E. Thirds to f. US Patent 482,444 (1892).

[6] Randell CF, White NC. Separators for electrochemical cells. WO Patent App. PCT/GB1996/001,318 (1996).

[7] Arora P, Zhang Z. Battery separators. Chem Rev. 2004;104:4419.

[8] Daniel C, Besenhard JO. Handbook of battery materials. Weinheim, Germany: Wiley, 2012.

[9] Huang X. Separator technologies for lithium-ion batteries. ] Solid State Electrochem. 2011;15:649.

[10] Dafler]R. The ultimate polymer application: Resin-bonded cellulose separators for lead-acid batteries. ] Appl Polym Sci. 1977;2551:21.

[11] Weber C], Ceiger S, Falusi S, Roth M. International Freiberg Conference on Electrochemical Storage Materials - ESTORM 2013. American Institute of Physics: AIP Conference Proceedings, 2014.

[12] Costa CM, Gomez Ribelles ], Lanceros-Méndez S, Appetecchi G, Scrosati B. Poly (vinylidene fluoride)-based, co-polymer separator electrolyte membranes for lithium-ion battery systems. J Power Sour. 2014;245:779.

[13] Ji Y, Jiang Y. Increasing the electrical conductivity of poly (vinylidene fluoride) by KrF excimer laser irradiation. Appl Phys Lett, 2006;89:221103.

[14] Bruce PC, Scrosati B, Tarascon JM. Nanomaterials for rechargeable lithium batteries. Angew Chem Int Ed. 2008;47:2930.

[15] Zhang SS. A review on the separators of liquid electrolyte Li-ion batteries. ] Power Sour. 2007;164:351.

[16] Wu MS, Liu KH, Wang YY, Wan CC. Heat dissipation design for lithium-ion batteries. ] Power Sour. 2002;109:160.

[17] Barnett B, Ofer D, Sriramulu S, Stringfellow R. Lithium-ion batteries, safety. In: Batteries for sustainability. New York: Springer, 2013:285318.

[18] Hueso KB, Armand M, Rojo T. High temperature sodium batteries: status, challenges and future trends. Energy \& Environ Sci. $2013 ; 6: 734$.

[19] Choudhury A, Chandra H, Arora A. Application of solid oxide fuel cell technology for power generation a review. Renewable Sustainable Energy Rev. 2013;20:430.

[20] Frost, Sullivan. High-tech materials alert 15th March 2013. Frost \& Sullivan, 2013.

[21] Roth EP, Doughty DH, Pile DL. Effects of separator breakdown on abuse response of 18650 Li-ion cells. J Power Sour. 2007;174:579.

[22] Orendorff C]. The role of separators in Lithium-ion cell safety. Interface-Electrochem Soc. 2012;21:61.

[23] Kim ]C, Son B, Mukherjee S, Schuppert N, Bates A, Kwon O, et al. A review of lithium and non-lithium based solid state batteries. ] Power Sour. 2015;282:299.

[24] Sun C, Liu ], Gong Y, Wilkinson DP, Zhang ]. Recent advances in all-solid-state rechargeable lithium batteries. Nano Energy. $2017 ; 33: 363$.

[25] Tubandt C, Lorenz E. Molekularzustand und elektrisches LeitvermoĖgen kristallisierter Salze. Z Phys Chem. 1914;24:513.

[26] Wen Z, Hu Y, Wu X, Han ], Gu Z. Main challenges for high performance NAS battery: materials and interfaces. Adv Funct Mater. 2013;23:1005.

[27] Kamaya N, Homma K, Yamakawa Y, Hirayama M, Kanno R, Yonemura M, et al. A lithium superionic conductor. Nat Mater. 2011;10:682.

[28] Fotheringham U, Schneider M, Hochrein O, Biedenbender S, Lauer S, Kluge M. Lithium ion-conductive glass ceramic, method for producing a lithium ion-conductive glass ceramic, ion conductor and use of the ion conductor. WO Patent App. PCT/EP2013/054,732 (2013).

[29] Uneme Y, Tamura S, Kawato T, Imanaka N. Moderate temperature operative sulfur dioxide gas sensor based on an $\mathrm{Ag}^{+}$ion conducting solid. Electrochem Solid-State Lett. 2011;14:138.

[30] Maier ]. Space charge regions in solid two-phase systems and their conduction contribution I. Conductance enhancement in the system ionic conductor-inertphase and application on $\mathrm{AgCl}_{\text {: }} \mathrm{Al}_{2} \mathrm{O}_{3}$ and $\mathrm{AgCl}: \mathrm{SiO}_{2}$. J Phys Chem Solids. 1985;46:309.

[31] Yao YFY, Kummer ]. Ion exchange properties of and rates of ionic diffusion in beta-alumina. ] Inorg Nucl Chem. 1967;29:2453

[32] de Jongh P, Blanchard D, Matsuo M, Udovic T, Orimo S. Complex hydrides as room-temperature solid electrolytes for rechargeable batteries. Appl Phys A. 2016;122:1.

[33] Lu X, Xia G, Lemmon ]P, Yang Z. Advanced materials for sodium-beta alumina batteries: status, challenges and perspectives. ] Power Sour. 2010;195:2431.

[34] Anantharamulu N, Rao KK, Rambabu G, Kumar BV, Radha V, Vithal M. A wide-ranging review on Nasicon type materials. ] Mater Sci. 2011;46:2821.

[35] Udovic T], Matsuo M, Tang WS, Wu H, Stavila V, Soloninin AV, et al. Exceptional superionic conductivity in disordered sodium Decahydro-closo-decaborate. Adv Mater. 2014;26:7622

[36] Knauth P. Inorganic solid Li ion conductors: an overview. Solid State lonics. 2009;180:911.

[37] Takada K. Progress and prospective of solid-state lithium batteries. Acta Mater. 2013;61:759.

[38] Menezes PV, Martin ], Schaefer M, Staesche H, Roling B, Weitzel KM. Bombardment induced ion transport Part II. Experimental potassium ion conductivities in borosilicate glass. Phys Chem Chem Phys. 2011;13:20123.

[39] Malavasi L, Fisher CA], Islam MS. Oxide-ion and proton conducting electrolyte materials for clean energy applications: structural and mechanistic features. Chem Soc Rev. 2010;39:4370.

[40] Maier ], Reichert B. Ionic transport in heterogeneously and homogeneously Doped Thallium (I)-Chloride. Berichte der Bunsengesellschaft für physikalische Chemie. 1986;90:666.

[41] Imanaka N, Tamura S, Adachi G. Ammonia sensor based on ionically exchanged $\mathrm{NH}_{4}^{+}$gallate solid electrolytes. Electrochem Solid-State Lett. 1998;1:282

[42] Banno N, Sakamoto T, Iguchi N, Sunamura H, Terabe K, Hasegawa T, et al. Diffusivity of Cu ions in solid electrolyte and its effect on the performance of nanometer-scale switch. Electron Devices, IEEE Trans. 2008;55:3283 
[43] Reddy MA, Fichtner M. Batteries based on fluoride shuttle. ] Mater Chem. 2011;21:17059.

[44] Patro L, Hariharan K. Fast fluoride ion conducting materials in solid state ionics: an overview. Solid State lonics. 2013;239:41.

[45] Rongeat C, Reddy MA, Witter R, Fichtner M. Nanostructured fluorite-type fluorides as electrolytes for fluoride ion batteries.] Phys Chem C. 2013;117:4943.

[46] Hibino T, Kobayashi K, Nagao M. An all-solid-state rechargeable aluminum-air battery with a hydroxide ion-conducting $\mathrm{Sb}(\mathrm{v})$-doped $\mathrm{SnP}_{2} \mathrm{O}_{7}$ electrolyte. J Mater Chem A. 2013;1:14844.

[47] Kharton VV, Marques FMB, Atkinson A. Transport properties of solid oxide electrolyte ceramics: a brief review. Solid State lonics. 2004;174:135.

[48] Fujii K, Esaki Y, Omoto K, Yashima M, Hoshikawa A, Ishigaki T, et al. New perovskite-related structure family of oxide-ion conducting materials $\mathrm{NdBaInO}_{4}$. Chem Mater. 2014;26:2488.

[49] Farrington G, Dunn B. Divalent beta"-aluminas: high conductivity solid electrolytes for divalent cations. Solid State lonics. 1982;7:267.

[50] Dunn B, Farrington C. Fast divalent ion conduction in $\mathrm{Ba}^{++}, \mathrm{Cd}^{++}$and Sr${ }^{++}$beta" aluminas. Mater Res Bull. 1980;15:1773.

[51] Ikeda S, Takahashi M, Ishikawa ], Ito K. Solid electrolytes with multivalent cation conduction. 1. Conducting species in Mg Zr PO4 system. Solid State lonics. 1987;23:125.

[52] Carrillo-Cabrera W, Thomas JO, Farrington CC. The ionic distribution in trivalent Cd ${ }^{3+} \beta^{\prime \prime}$-alumina. Solid State lonics. 1983;9:245.

[53] Dunn B, Farrington G. Trivalent ion exchange in beta" alumina. Solid State lonics. 1983;9:223.

[54] Sattar S, Chosal B, Underwood M, Mertwoy H, Saltzberg M, Frydrych W, et al. Synthesis of Di-and trivalent $\beta^{\prime \prime}$-aluminas by ion exchange. J Solid State Chem. 1986;65:231

[55] Imanaka N, Tamura S, Nunotani N. Multivalence cation conductors. Encycl Appl Electrochem. 2014;1334-9.

[56] Neiman AY, Pestereva N, Zhou Y, Nechaev D, Koteneva E, Vanec K, et al. The nature and the mechanism of ion transfer in tungstates $\mathrm{Me}^{2+} \mathrm{WO}_{4}(\mathrm{Ca}, \mathrm{Sr}, \mathrm{Ba})$ and $\mathrm{Me}^{3+}{ }_{2} \mathrm{WO}^{3}(\mathrm{Al}, \mathrm{Sc}, \mathrm{In})$ according to the data acquired by the tubandt method. Russ ] Electrochem. 2013;49:895.

[57] Nestler T, Fedotov S, Leisegang T, Meyer DC. Towards A ${ }^{3+}$ mobility in crystalline solids: critical review and analysis. Crit Rev Solid State Mater Sci. 2018.

[58] Hayashi A, Ohtomo T, Mizuno F, Tadanaga M, Tatsumisago K. All-solid-state Li/S batteries with highly conductive glass-ceramic electrolytes. Electrochem Commun. 2003;5:701.

[59] Machida N, Kobayashi K, Nishikawa Y, Shigematsu T. Electrochemical properties of sulfur as cathode materials in a solid-state lithium battery with inorganic solid electrolytes. Solid State lonics. 2004;175:247.

[60] Hayashi A, Ohtsubo R, Ohtomo T, Mizuno F, Tatsumisago M. All-solid-state rechargeable lithium batteries with $\mathrm{Li}_{2} \mathrm{~S}$ as a positive electrode material. J Power Sour. 2008;183:422.

[61] Hautier C, Jain A, Chen H, Moore C, Ong SP, Ceder G. Novel mixed polyanions lithium-ion battery cathode materials predicted by highthroughput ab initio computations. ] Mater Chem. 2011;21:17147.

[62] Mori R. A new structured aluminium-air secondary battery with a ceramic aluminium ion conductor. RSC Adv. 2013:3:11547.

[63] Shimonishi Y, Zhang T, Imanishi N, Im D, Lee D], Hirano A, et al. A study on lithium/air secondary batteriesstability of the NASICON-type lithium ion conducting solid electrolyte in alkaline aqueous solutions. J Power Sour. 2011;196:5128.

[64] Technology and market forecast of separators for rechargeable lithium ion batteries (2009-2014). Bundang-gu, Seongnam-si, Korea: Solar \& Energy Co., Ltd, 2010.

[65] Kim H, Ding Y, Kohl PA. LiSICON-ionic liquid electrolyte for lithium ion battery. ] Power Sour. 2012;198:281.

[66] Gao ], Chu G, He M, Zhang S, Xiao R, Li H, et al. Screening possible solid electrolytes by calculating the conduction pathways using bond valence method. Sci China Phys Mech Astron. 2014;57:1526.

[67] Barber MN, Ninham BW. Random and restricted walks: theory and applications, volume 10. New York: CRC Press, 1970.

[68] Koiwa M, Ishioka S. Random walk properties of lattices and correlation factors for diffusion via the vacancy mechanism in crystals. ] Stat Phys 1983;30:477.

[69] Mehrer H. Diffusion in solids: fundamentals, methods, materials, diffusion-controlled processes, volume 155. Berlin, Heidelberg, Cermany: Springer Science \& Business Media, 2007.

[70] Almond D, Duncan C, West A. The determination of hopping rates and carrier concentrations in ionic conductors by a new analysis of ac conductivity. Solid State lonics. 1983;8:159.

[71] Balluffi RW, Allen S, Carter WC. Kinetics of materials. Hoboken, USA: John Wiley \& Sons, 2005.

[72] Xie H, Alonso ]A, Li Y, Fernandez-Diaz MT, Goodenough ]B. Lithium distribution in aluminum-free cubic $\mathrm{Li}_{7} \mathrm{La}_{3} \mathrm{Zr}_{2} \mathrm{O}_{12}$. Chem Mater. 2011;23:3587.

[73] Xu M, Park MS, Lee JM, Kim TY, Park YS, Ma E. Mechanisms of Li+ transport in garnet-type cubic $\mathrm{Li}_{3+\mathrm{x}} \mathrm{La}_{3} \mathrm{M}_{2} \mathrm{O}_{12}(\mathrm{M}=\mathrm{Te}, \mathrm{Nb}, \mathrm{Zr})$. Phys Rev B. 2012;85:052301.

[74] Whiteley JM, Woo ]H, Hu E, Nam KW, Lee SH. Empowering the lithium metal battery through a silicon-based superionic conductor. ] Electrochem Soc. 2014;161:A1812.

[75] Wang Y, Richards WD, Ong SP, Miara L], Kim JC, Mo Y, et al. Design principles for solid-state lithium superionic conductors. Nat Mater. 2015;14:1026.

[76] Sata N, Eberman K, Eberl K, Maier ]. Mesoscopic fast ion conduction in nanometre-scale planar heterostructures. Nature. 2000;408:946.

[77] Maier ]. Nanoionics: ion transport and electrochemical storage in confined systems. Nat Mater. 2005;4:805.

[78] Pennycook T], Beck M], Varga K, Varela M, Pennycook S], Pantelides ST. Origin of colossal ionic conductivity in oxide multilayers: interface induced sublattice disorder. Phys Rev Lett. 2010;104:115901.

[79] Adams S. Ultrafast lithium migration in surface modified LiFePO 4 by heterogeneous doping. Appl Energy. 2012;90:323.

[80] Adepalli KK, Kelsch M, Merkle R, Maier ]. Enhanced ionic conductivity in polycrystalline $\mathrm{TiO}_{2}$ by one-dimensional doping. Phys Chem Chem Phys. 2014;16:4942.

[81] Armstrong R, Bulmer R, Dickinson T. Fast ion transport in solids. Amsterdam: North Holland Publishing, 1973.

[82] Coodenough ], Hong HP, Kafalas ]. Fast $\mathrm{Na}^{+}$-ion transport in skeleton structures. Mater Res Bull. 1976;11:203.

[83] Adachi G, Imanaka N, Aono H. Fast Li+ conducting ceramic electrolytes. Adv Mater. 1996;8:127. 
[84] Levi E, Levi M, Chasid O, Aurbach D. A review on the problems of the solid state ions diffusion in cathodes for rechargeable Mg batteries. J Electroceram. 2009;22:13.

[85] Adams S, Rao RP. Structural requirements for fast lithium ion migration in $\mathrm{Li}_{10} \mathrm{CeP}_{2} \mathrm{~S}_{12}$. J Mater Chem. 2012;22:7687.

[86] Guin M, Tietz F. Survey of the transport properties of sodium superionic conductor materials for use in sodium batteries.] Power Sour. 2015;273:1056.

[87] Rong Z, Malik R, Canepa P, Sai Gautam G, Liu M, Jain A, et al. Materials design rules for multivalent ion mobility in intercalation structures. Chem Mater. 2015;27:6016.

[88] Meutzner F, Münchgesang W, Leisegang T, Schmid R, Zschornak M, Ureña de Vivanco M, et al. Identification of solid oxygen-containing Na-electrolytes: an assessment based on crystallographic and economic parameters. Cryst Res Technol. 2017;52:1.

[89] Shannon RT. Revised effective ionic radii and systematic studies of interatomic distances in halides and chalcogenides. Acta Crystallogr Sect A: Cryst Phys Diffr Theor Cen Crystallogr. 1976;32:751.

[90] Liu S, Hu J, Yan N, Pan C, Li G, Gao X. Aluminum storage behavior of anatase $\mathrm{TiO}_{2}$ nanotube arrays in aqueous solution for aluminum ion batteries. Energy Environ Sci. 2012;5:9743.

[91] Geng L, Lv G, Xing X, Guo ]. Reversible electrochemical intercalation of aluminum in Mo6S8. Chem Mater. 2015;27:4926.

[92] Meutzner F, Nestler T, Zschornak M, Canepa P, Gautam CS, Leoni S, et al. Theoretical methods for battery material identification and analysis in electrochemical storage materials: from crystallography to manufacturing technology. Berlin: De Gruyter Oldenbourg Publishing House, 2018.

[93] Imanaka N, Kobayashi Y, Adachi CY. A direct evidence for trivalent ion conduction in solids. Chem Lett. 1995;24:433.

[94] Imanaka N, Tamura S. Development of multivalent ion conducting solid electrolytes. Bull Chem Soc ]pn. 2011;84:353.

[95] Driscoll D], Islam MS, Slater PR. Simulation and conductivity studies of defects and ion transport in $\mathrm{Sc}_{2}\left(\mathrm{WO}_{4}\right)_{3}$. Solid State lonics. 2005;176;539.

[96] Adams S. From bond valence maps to energy landscapes for mobile ions in ion-conducting solids. Solid State lonics. 2006;177:1625.

[97] Zhou Y, Adams S, Rao RP, Edwards DD, Neiman A, Pestereva N. Charge transport by polyatomic anion diffusion in $\mathrm{Sc}_{2}\left(\mathrm{WO}_{4}\right)_{3}$. Chem Mater. 2008;20:6335.

[98] Zhou Y, Rao RP, Adams S. Mechanism of defect formation and polyanion transport in solid scandium tungstate type oxides. Monatshefte für Chemie-Chem Mon. 2009;140:1017.

[99] Zhou Y, Rao RP, Adams S. Intrinsic polyatomic defects in $\mathrm{Sc}_{2}\left(\mathrm{WO}_{4}\right)_{3}$. Solid State lonics. 2011;192:34.

[100] Zhou Y, Neiman A, Adams S. Novel polyanion conduction in $\mathrm{Sc}_{2}\left(\mathrm{WO}_{4}\right)_{3}$ type negative thermal expansion oxides. Phys Status Solidi (b). 2011;248:130.

[101] Yada C, Ohmori A, Ide K, Yamasaki H, Kato T, Saito T, et al. Dielectric modification of 5V-class cathodes for high-voltage all-solid-state lithium batteries. Adv Energy Mater. 2014;4:9.

[102] Takada K, Ohta N, Tateyama Y. Recent progress in interfacial nanoarchitectonics in solid-state batteries.] Inorg Organomet Polym Mater. 2015;25:205.

[103] Lepley N, Holzwarth N. Modeling interfaces between solids: application to Li battery materials. Phys Rev B. 2015;92:214201.

[104] Takada K, Ohno T. Experimental and computational approaches to interfacial resistance in solid-state batteries. Front Energy Res. 2016;4:10.

[105] Wenzel S, Leichtweiß T, Weber DA, Sann ], Zeier WC, Janek ]. Interfacial reactivity benchmarking of the sodium ion conductors $\mathrm{Na}_{3} \mathrm{PS}_{4}$ and sodium $\beta$-alumina for protected sodium metal anodes and sodium all-solid-state batteries. ACS Appl Mater Interface. 2016.

[106] Aurbach D. The role of surface films on electrodes in Li-ion batteries. In: Advances in Lithium-ion batteries. New York: Springer, 2002: 7-77.

[107] Zhang JG, Xu W, Henderson WA. Lithium metal anodes and rechargeable lithium metal batteries. Switzerland: Springer, 2017.

[108] Guo X, Maier ]. Grain boundary blocking effect in zirconia: a Schottky barrier analysis. ] Electrochem Soc. 2001;148:E121.

[109] Cuo X, Waser R. Electrical properties of the grain boundaries of oxygen ion conductors: acceptor-doped zirconia and ceria. Prog Mater Sci. 2006;51:151.

[110] Guo X, Sigle W, Fleig ], Maier ]. Role of space charge in the grain boundary blocking effect in doped zirconia. Solid State lonics. 2002;154:555.

[111] Uvarov N. Surface disordering of classic and superionic crystals: a description in the framework of the Stern model. Russ ] Electrochem. 2007:43:368.

[112] Uvarov N. Estimation of the surface potential in superionic oxide conductors using the Stern model. Solid State lonics. 2008;179:783.

[113] Wagner ], Jr. Composite materials as solid electrolytes. In: Solid state batteries. Dordrecht, Netherlands: Springer, 1985: 77-90.

[114] Maier ]. Ionic conduction in space charge regions. Prog Solid State Chem. 1995;23:171.

[115] Uvarov N. Composite solid electrolytes: recent advances and design strategies. J Solid State Electrochem. 2011;15:367.

[116] Liang C, Joshi A, Hamilton N. Solid-state storage batteries. ] Appl Electrochem. 1978;8:445.

[117] Crompton TP. Battery reference book. Oxford, Great Britain: Newnes, 2000. eBook ISBN: 9780080499956.

[118] Uvarov N. Estimation of composites conductivity using a general mixing rule. Solid State lonics. 2000;136:1267.

[119] Uvarov NF. Estimation of electrical properties of composite solid electrolytes of different morphologies. Solid State lonics. $2017 ; 302: 19$.

[120] Konisheva E, Neiman A, Corbunova E.. Transport processes and surface transformation at the CaWO4|WO3 interface. Solid State lonics. 2003;157:45.

[121] Neiman AY, Pestereva N, Sharafutdinov A, Kostikov YP. Conduction and transport numbers in metacomposites $\mathrm{MeWO} 4 £ \mathrm{WO} 3(\mathrm{Me}=\mathrm{Ca}$, $\mathrm{Sr}, \mathrm{Ba})$. Russ ] Electrochem. 2005;41:598.

[122] Neiman AY, Uvarov N, Pestereva N. Solid state surface and interface spreading: an experimental study. Solid State lonics. $2007 ; 177: 3361$.

[123] Uvarov N. Phenomenological description of transport properties of three-phase composites. Russ ] Electrochem. 2017:53:700.

[124] Ulihin A, Mateyshina YG, Uvarov N. All-solid-state asymmetric supercapacitors with solid composite electrolytes. Solid State lonics. 2013;251:62.

[125] Choi JW, Aurbach D. Promise and reality of post-lithium-ion batteries with high energy densities. Nat Rev Mater. 2016;1:16013. 
[126] Ling C, Banerjee D, Matsui M. Study of the electrochemical deposition of Mg in the atomic level: why it prefers the non-dendritic morphology. Electrochim Acta. 2012;76:270.

[127] Aurbach D, Lu Z, Schechter A, Gofer Y, Gizbar H, Turgeman R, et al. Prototype systems for rechargeable magnesium batteries. Nature. 2000;407:724.

[128] Aurbach D, Suresh CS, Levi E, Mitelman A, Mizrahi O, Chusid O, et al. Progress in rechargeable magnesium battery technology. Adv Mater. 2007;19:4260.

[129] Chusid O, Gofer Y, Gizbar H, Vestfrid Y, Levi E, Aurbach D, et al. Solid-state rechargeable magnesium batteries. Adv Mater. $2003 ; 15: 627$.

[130] Canepa P, Sai Gautam C, Hannah DC, Malik R, Liu M, Gallagher KC, et al. Odyssey of multivalent cathode materials: open questions and future challenges. Chem Rev. 2017;117:4287.

[131] Muldoon ], Bucur CB, Gregory T. Quest for nonaqueous multivalent secondary batteries: magnesium and beyond. Chem Rev. 2014;114:11683.

[132] Yoo HD, Shterenberg I, Gofer Y, Gershinsky G, Pour N, Aurbach D. Mg rechargeable batteries: an on-going challenge. Energy Environ Sci. 2013;6:2265.

[133] Ikeda S, Takahashi M, Ishikawa ], Ito K. Solid electrolytes with multivalent cation conduction. 1. Conducting species in MgZrPO $_{4}$ system. Solid State lonics. 1987;23:125

[134] Imanaka N, Okazaki Y, Adachi CY. Divalent magnesium ion conducting characteristics in phosphate based solid electrolyte composites. ] Mater Chem. 2000;10:1431.

[135] Imanaka N, Okazaki Y, Adachi C. Optimization of divalent magnesium ion conduction in phosphate based polycrystalline solid electrolytes. Ionics. 2001;7:440.

[136] Mielewczyk A, Molin S, Cdula K, Jasiński G, Kusz B, Jasiński P, et al. Structure and electric properties of double magnesium zirconium orthophosphate. Mater Ceram. 2010;62:477.

[137] Cobechiya E, Sukhanov M, Petkov V, Kabalov YK. Crystal structure of the double magnesium zirconium orthophosphate at temperatures of 298 and 1023 K. Crystallogr Rep. 2008;53:53.

[138] Takada K. Solid electrolytes and solid-state batteries. In: AIP Conference Proceedings, volume 1765. AIP Publishing, 2016: 020008.

[139] Mohtadi R, Mizuno F. Magnesium batteries: current state of the art, issues and future perspectives. Beilstein ] Nanotechnol. $2014 ; 5: 1291$.

[140] Shao Y, Rajput NN, Hu ], Hu M, Liu T, Wei Z, et al. Nanocomposite polymer electrolyte for rechargeable magnesium batteries. Nano Energy. 2015;12:750.

[141] Mohtadi R, Matsui M, Arthur TS, Hwang S]. Magnesium borohydride: from hydrogen storage to magnesium battery. Angew Chem Int Ed. 2012;51:9780.

[142] Lu Z, Ciucci F. Metal borohydrides as electrolytes for solid-state Li, Na, Mg, and Ca batteries: a first-principles study. Chem Mater. 2017;29:9308.

[143] Ikeshoji T, Tsuchida E, Takagi S, Matsuo M, Orimo SI. Magnesium ion dynamics in $M g\left(\mathrm{BH}_{4}\right)_{2(1-x)} \mathrm{X}_{2 \mathrm{x}}(\mathrm{X}=\mathrm{Cl} \text { or AlH })_{4}$ from first-principles molecular dynamics simulations. RSC Adv. 2014;4:1366.

[144] Higashi S, Miwa K, Aoki M, Takechi K. A novel inorganic solid state ion conductor for rechargeable Mg batteries. Chem Commun. 2014;50:1320.

[145] Roedern E, Kühnel RS, Remhof A, Battaglia C. Magnesium ethylenediamine borohydride as solid-state electrolyte for magnesium batteries. Sci Rep. 2017;7.

[146] Chen ], Chua YS, Wu H, Xiong Z, He T, Zhou W, et al. Synthesis, structures and dehydrogenation of magnesium borohydrideethylenediamine composites. Int ] Hydrogen Energy. 2015;40:412.

[147] Lide D. CRC handbook of chemistry and physics, 88th Ed. Boca Raton: CRC Press, 2007.

[148] Ciorgini MG, Pelletti MR, Paliani G, Cataliotti RS. Vibrational spectra and assignments of ethylene-diamine and its deuterated derivatives. J Raman Spectrosc. 1983;14:16

[149] Iwamoto T, Shriver DF. Vibrational spectra of catena- $\mu$-Ethylenediamine complexes of Zinc(II), Cadmium(II), and Mercury(II) with the formula $M\left(\right.$ en) $X_{2}$. Inorg Chem. 1971;10:2428.

[150] Allen A, SenoffC. Infrared spectra of tris-ethylenediamine complexes of Ruthenium(II). Can ] Chem. 1965;43:888.

[151] Bennett AM, Foulds CA, Thornton DA, Watkins CM. The infrared spectra of ethylenediamine complexesll. Tris-, bis-and mono (ethylenediamine) complexes of metal(II) halides. Spectrochim Acta Part A: Mol Spectrosc. 1990;46:13.

[152] Skripov AV, Soloninin AV, Ley MB, Jensen TR, Filinchuk Y. Nuclear magnetic resonance studies of $\mathrm{BH}_{4}$ reorientations and Li diffusion in $\mathrm{LiLa}\left(\mathrm{BH}_{4}\right)_{3} \mathrm{Cl}$. J Phys Chem C. 2013;117:14965.

[153] Hansen BR, Paskevicius M, Li HW, Akiba E, Jensen TR. Metal boranes: progress and applications. Coord Chem Rev. 2016;323:60.

[154] Mannhart ], Schlom DG. Oxide-Tausendsassas für die Elektronik. Phys ]. 2005;4:45.

[155] Lu X, Xia G, Lemmon ]P, Yang Z. Advanced materials for sodium-beta alumina batteries: status, challenges and perspectives. ] Power Sour. 2010;195:2431.

[156] Tucker MC. Progress in metal-supported solid oxide fuel cells: a review. ] Power Sour. 2010;195:4570.

[157] Kraytsberg A, Ein Eli Y. Higher, stronger, better: a review of $5 \mathrm{~V}$ cathode materials for advanced Lithium-ion batteries. Adv Energy Mater 2012;2:922.

[158] Zhang Y, Feng H, Wu X, Wang L, Zhang A, Xia T, et al. Progress of electrochemical capacitor electrode materials: a review. Int ] Hydrogen Energy. 2009;34:4889.

[159] Cheng F, Chen J. Metal-air batteries: from oxygen reduction electrochemistry to cathode catalysts. Chem Soc Rev. 2012;41:2172.

[160] Hanzig ], Zschornak M, Nentwich M, Hanzig F, Gemming S, Leisegang T, et al. Strontium titanate: an all-in-one rechargeable energy storage material. ] Power Sour. 2014;267:700.

[161] Valov I, Linn E, Tappertzhofen S, Schmelzer ], Van den Hurk S, Lentz F, et al. Nanobatteries in redox-based resistive switches require extension of memristor theory. Nat Commun. 2013;4:1771

[162] Hanzig ], Zschornak M, Hanzig F, Mehner E, Stöcker H, Abendroth B, et al. Migration-induced field-stabilized polar phase in strontium titanate single crystals at room temperature. Phys Rev B. 2013;88:024104. 
[163] Hanzig ], Mehner S, Jachalke E, Hanzig F, Zschornak M, Richter C, et al. Dielectric to pyroelectric phase transition induced by defect migration. J Phys. 2015;17:023036.

[164] Kröger F. A., Vink H. J. Solid-State Physics. In F. Seitz and D. Turnbull (eds). New York: Academic Press Inc. 1956;3:307.

[165] Waser R, Dittmann R, Staikov G, Szot K. Redox-based resistive switching memories-nanoionic mechanisms, prospects, and challenges. Adv Mater. 2009;21:2632.

[166] Blanc ], Staebler DL. Electrocoloration in $\mathrm{SrTiO}_{3}$ : vacancy drift and oxidation-reduction of transition metals. Phys Rev B. $1971 ; 4: 3548$.

[167] Mohapatra SK, Wagner S. Electrochromism in nickel-doped strontium titanate. ] Appl Phys. 1979;50:5001.

[168] Hanzig ], Zschornak M, Mehner E, Hanzig F, Münchgesang W, et al. The anisotropy of oxygen vacancy migration in SrTiO 3 . J Phys: Condens Matter. 2016;28:225001.

[169] Xu K. Nonaqueous liquid electrolytes for lithium-based rechargeable batteries. Chem Rev. 2004;104:4303.

[170] Xu K. Electrolytes and interphases in Li-ion batteries and beyond. Chem Rev. 2014;114:11503

[171] Armand M, Endres F, MacFarlane DR, Ohno H, Scrosati B. lonic-liquid materials for the electrochemical challenges of the future. Nat Mater. 2009;8:621.

[172] Sakaebe H, Matsumoto H, Tatsumi K. Application of room temperature ionic liquids to Li batteries. Electrochim Acta. $2007 ; 53: 1048$.

[173] Balducci A, Dugas R, Taberna P, Simon P, Plée D, Mastragostino M, et al. High temperature carboncarbon supercapacitor using ionic liquid as electrolyte. J Power Sour. 2007;165:922.

[174] Brandt A, Balducci A. Theoretical and practical energy limitations of organic and ionic liquid-based electrolytes for high voltage electrochemical double layer capacitors. J Power Sour. 2014;250:343.

[175] Appetecchi GB, Montanino M, Passerini S. Ionic liquid-based electrolytes for high energy, safer Lithium batteries. In: ACS Symposium Series, volume 1117. ACS Publications, 2012: 67-128.

[176] Eshetu CG, Grugeon S, Kim H, Jeong S, Wu L, Gachot G, et al. Comprehensive insights into the reactivity of electrolytes based on sodium ions. ChemSusChem. 2016;9:462.

[177] Chen Y, Zhang X, Zhang D, Yu P, Ma Y. High performance supercapacitors based on reduced graphene oxide in aqueous and ionic liquid electrolytes. Carbon. 2011;49:573.

[178] Xu B, Wu F, Chen R, Cao G, Chen S, Yang Y. Mesoporous activated carbon fiber as electrode material for high-performance electrochemical double layer capacitors with ionic liquid electrolyte. J Power Sour. 2010;195:2118.

[179] Pettersson F, Keskinen ], Remonen T, von Hertzen L, Jansson E, Tappura K, et al. Printed environmentally friendly supercapacitors with ionic liquid electrolytes on paper. ] Power Sour. 2014;271:298.

[180] Yamamoto T, Nohira T, Hagiwara R, Fukunaga A, Sakai S, Nitta K, et al. Chargedischarge behavior of tin negative electrode for a sodium secondary battery using intermediate temperature ionic liquid sodium bis(fluorosulfonyl)amidepotassium bis(fluorosulfonyl)amide. ) Power Sour. 2012;217:479.

[181] Hasa I, Passerini S, Hassoun ]. Characteristics of an ionic liquid electrolyte for sodium-ion batteries. ] Power Sour. 2016;303:203.

[182] Monti D, Jónsson E, Palacín MR, Johansson P. Ionic liquid based electrolytes for sodium-ion batteries: $\mathrm{Na}^{+}$solvation and ionic conductivity. J Power Sour. 2014;245:630.

[183] Menne S, Schroeder M, Vogl T, Balducci A. Carbonaceous anodes for lithium-ion batteries in combination with protic ionic liquidsbased electrolytes. J Power Sour. 2014;266:208.

[184] Menne S, Vogl T, Balducci A. The synthesis and electrochemical characterization of bis(fluorosulfonyl)imide-based protic ionic liquids. Chem Commun. 2015;51:3656.

[185] Reale P, Fernicola A, Scrosati B. Compatibility of the $\mathrm{Py}_{24}$ TFSILiTFSI ionic liquid solution with $\mathrm{Li}_{4} \mathrm{Ti}_{5} \mathrm{O}_{12}$ and LiFePO $\mathrm{C}_{4}$ lithium ion battery electrodes. J Power Sour. 2009;194:182.

[186] Montanino M, Moreno M, Carewska M, Maresca C, Simonetti E, Lo Presti R, et al. Mixed organic compound-ionic liquid electrolytes for lithium battery electrolyte systems. J Power Sour. 2014;269:608.

[187] Elia CA, Bernhard R, Hassoun ]. A lithium-ion oxygen battery using a polyethylene glyme electrolyte mixed with an ionic liquid. RSC Adv. 2015;5:21360.

[188] Agostini M, Ulissi U, Di Lecce D, Ahiara Y, Ito S, Hassoun ], et al. A Lithium-ion battery based on an lonic liquid electrolyte, Tin-Carbon nanostructured anode, and $\mathrm{Li}_{2} \mathrm{O}-\mathrm{ZrO}_{2}$-coated $\mathrm{Li}\left[\mathrm{Ni}_{0.8} \mathrm{Co}_{0.15} \mathrm{Al}_{0.05}\right]_{2}$ Cathode. Energy Technol. 2015;3:632.

[189] Di Lecce D, Brutti S, Panero S, Hassoun ]. A new Sn-C/LiFe ${ }_{0.1} \mathrm{Co}_{0.9} \mathrm{PO}_{4}$ full lithium-ion cell with ionic liquid-based electrolyte. Mater Lett. 2015;139:329.

[190] Nádherná M, Reiter ], Moškon ], Dominko R. Lithium bis(fluorosulfonyl)imidePYR ${ }_{14}$ TFSI ionic liquid electrolyte compatible with graphite. J Power Sour. 2011;196:7700.

[191] Reiter ], Nádherná M, Dominko R. Craphite and $\mathrm{LiCO}_{1 / 3} \mathrm{Mn}_{1 / 3} \mathrm{Ni}_{1 / 3} \mathrm{O}_{2}$ electrodes with piperidinium ionic liquid and lithium bis(fluorosulfonyl)imide for Li-ion batteries. ] Power Sour. 2012;205:402.

[192] Chagas LC, Buchholz D, Wu L, Vortmann B, Passerini S. Unexpected performance of layered sodium-ion cathode material inionic liquidbased electrolyte. J Power Sour. 2014;247:377.

[193] Kim JK, Mueller F, Kim H, Jeong S, Park JS, Passerini S, et al. Eco-friendly energy storage system: seawater and lonic Liquid electrolyte. ChemSusChem. 2016;9:42.

[194] Wang P, Zakeeruddin SM, Comte P, Exnar I, Grätzel M. Gelation of ionic liquid-based electrolytes with silica nanoparticles for quasisolid-state dye-sensitized solar cells. J Am Chem Soc. 2003;125:1166.

[195] Galiński M, Lewandowski A, Stępniak I. Ionic liquids as electrolytes. Electrochim Acta. 2006;51:5567.

[196] Xue L, Padgett CW, DesMarteau DD, Pennington WT. Synthesis and structures of alkali metal salts of bis [(trifluoromethyl) sulfonyl] imide. Solid State Sci. 2002;4:1535.

[197] Zhou Q, Boyle PD, Malpezzi L, Mele A, Shin JH, Passerini S, et al. Phase behavior of lonic LiquidLiX mixtures: Pyrrolidinium cations and TFSI anions linking structure to transport properties. Chem Mater. 2011;23:4331.

[198] Eftekhari A, Liu Y, Chen P. Different roles of ionic liquids in lithium batteries. ] Power Sour. 2016;334:221. 
[199] Bhatt AI, May I, Volkovich VA, Hetherington ME, Lewin B, Thied RC, et al. Group 15 quaternary alkyl bistriflimides: ionic liquids with potential application in electropositive metal deposition and as supporting electrolytes. J Chem Soc Dalton Trans. 2002;24:4532.

[200] Matsumoto H, Yanagida M, Tanimoto K, Nomura M, Kitagawa Y, Miyazaki Y. Highly conductive room temperature molten salts based on small trimethylalkylammonium cations and bis (trifluoromethylsulfonyl) imide. Chem Lett. 2000;29:922.

[201] Kim ]K, Matic A, Ahn JH, Jacobsson P. An imidazolium based ionic liquid electrolyte for lithium batteries. ] Power Sour. 2010;195:7639.

[202] Seki S, Ohno Y, Kobayashi Y, Miyashiro H, Usami A, Mita Y, et al. Imidazolium-based room-temperature lonic liquid for Lithium secondary batteries. J Electrochem Soc. 2007;154:A173.

[203] Seki S, Kobayashi Y, Miyashiro H, Ohno Y, Usami A, Mita Y, et al. Lithium secondary batteries using modified-imidazolium roomtemperature ionic liquid. J Phys Chem B. 2006;110:10228.

[204] Yim T, Lee HY, Kim H], Mun ], Kim S, Oh SM, et al. Synthesis and properties of pyrrolidinium and piperidinium bis (trifluoromethanesulfonyl) imide ionic liquids with allyl substituents. Bull Korean Chem Soc. 2007;28:1567.

[205] Fang S, Yang L, Wei C, Peng C, Tachibana K, Kamijima K. Low-viscosity and low-melting point asymmetric trialkylsulfonium based ionic liquids as potential electrolytes. Electrochem Commun. 2007;9:2696.

[206] Ye H, Huang ], Xu ]], Khalfan A, Greenbaum SG. Li ion conducting polymer gel electrolytes based on ionic liquid/PVDF-HFP blends. ] Electrochem Soc. 2007;154:A1048.

[207] Tsunashima K, Yonekawa F, Sugiya M. Lithium secondary batteries using a Lithium Nickelate-based cathode and phosphonium ionic liquid electrolytes. Electrochem Solid-State Lett. 2009;12:A54.

[208] Wilkes ]S, Zaworotko M]. Air and water stable 1-ethyl-3-methylimidazolium based ionic liquids. ] Chem Soc Chem Commun. 1992;13:965.

[209] Henderson WA, Passerini S. Phase behavior of ionic liquid LiX mixtures: Pyrrolidinium cations and TFSI - anions. Chem Mater. 2004;16:2881.

[210] Elia CCA, Ulissi U, Mueller F, Reiter ], Tsiouvaras N, Sun YK, et al. A Long-life lithium ion battery with enhanced electrode/electrolyte interface by using an ionic liquid solution. Chem Eur ]. 2016;22:6808.

[211] Appel R, Becke-Coehring M, Eisenhauer G, Hartenstein ]. Imidobisschwefelsäurechlorid. Chem Ber. 1962;95:625.

[212] Michot C, Armand M, Sanchez JY, Choquette Y, Gauthier M. Materiau a conduction ionique presentant de bonnes proprietes anticorrosion, 1995

[213] Elia CA, Ulissi U, Jeong S, Passerini S, Hassoun ]. Exceptional long-life performance of lithium-ion batteries using ionic liquid-based electrolytes. Energy Environ Sci. 2016;9:3210.

[214] Piper DM, Evans T, Leung K, Watkins T, Olson ], Kim SC, et al. Stable silicon-ionic liquid interface for next-generation lithium-ion batteries. Nat Commun. 2015;6:6230.

[215] Larcher D, Tarascon JM. Towards greener and more sustainable batteries for electrical energy storage. Nat Chem. 2015;7:19.

[216] Tarascon JM. Is lithium the new gold? Nat Chem. 2010;2:510.

[217] Yabuuchi N, Kubota K, Dahbi M, Komaba S. Research development on sodium-ion batteries. Chem Rev. 2014;114:11636.

[218] Nithya C, Gopukumar S. Sodium ion batteries: a newer electrochemical storage. Wiley Interdiscip Rev: Energy Environ. 2015;4:253.

[219] Hasa I, Buchholz D, Passerini S, Hassoun ]. A comparative study of layered transition metal oxide cathodes for application in sodium-ion battery. ACS Appl Mater Interface. 2015;7:5206.

[220] Hasa I, Passerini S, Hassoun ]. A rechargeable sodium-ion battery using a nanostructured SbC anode and P2-type layered $\left[\mathrm{Na}_{0.6} \mathrm{Ni}_{0.22} \mathrm{Fe}_{0.11} \mathrm{Mn}_{0.66} \mathrm{O}_{2}\right.$ cathode. RSC Adv. 2015;5:48928.

[221] Dunn B, Kamath H, Tarascon JM. Electrical energy storage for the grid: a battery of choices. Science (New York, N.Y.) 2011;334:928.

[222] Zhao Q, Hu Y, Zhang K, Chen ]. Potassium sulfur batteries: a new member of room-temperature rechargeable metal sulfur batteries. Inorg Chem. 2014;53:9000.

[223] Ren X, Wu Y. A low-overpotential potassium oxygen battery based on potassium superoxide. ] Am Chem Soc. 2013;135:2923.

[224] Ponrouch A, Frontera C, Bardé F, Palacín MR. Towards a calcium-based rechargeable battery. Nat Mater. 2015;15:169.

[225] See KA, Gerbec ]A, Jun YSS, Wudl F, Stucky GD, Seshadri R. A high capacity calcium primary cell based on the Ca-S system. Adv Energy Mater. 2013;3:1056.

[226] Aurbach D, Gizbar H, Schechter A, Chusid O, Gottlieb HE, Gofer Y, et al. Electrolyte solutions for rechargeable magnesium batteries based on organomagnesium chloroaluminate complexes. ] Electrochem Soc. 2002;149:A115.

[227] Lin MC, Cong M, Lu B, Wu Y, Wang DY, Guan M, et al. An ultrafast rechargeable aluminium-ion battery. Nature. 2015;520:325.

[228] Sun H, Wang W, Yu Z, Yuan Y, Wang S, Jiao S. A new aluminium-ion battery with high voltage, high safety and low cost. Chem Commun. 2015;51:11892.

[229] Shkolnikov E, Zhuk A, Vlaskin M. Aluminum as energy carrier: feasibility analysis and current technologies overview. Renewable Sustainable Energy Rev. 2011;15:4611.

[230] Li Q, Bjerrum N]. Aluminum as anode for energy storage and conversion: a review. ] Power Sour. 2002;110:1.

[231] U.S. Ceological Survey. Mineral commodity summaries 2015: U.S. Geological Survey. 2015:196. http://dx.doi.org/10.3133/70140094

[232] Fleischer M. Recent estimates of the abundances of the elements in this earth's crust. Ceol Surv Circ. 1953;285.

[233] MacFarlane DR, Tachikawa N, Forsyth M, Pringle JM, Howlett PC, Elliott CD, et al. Energy applications of ionic liquids. Energy Environ Sci. 2014;7:232.

[234] Otaegui L, Goikolea E, Aguesse F, Armand M, Rojo T, Singh C. Effect of the electrolytic solvent and temperature on aluminium current collector stability: a case of sodium-ion battery cathode. J Power Sour. 2015;297:168.

[235] Saha P, Datta MK, Velikokhatnyi OI, Manivannan A, Alman D, Kumta PN. Rechargeable magnesium battery: current status and key challenges for the future. Prog Mater Sci. 2014;66:1.

[236] Ciffin CA. Ionic liquid-based electrolytes for “beyond lithium” battery technologies. ] Mater Chem A. 2016;4:13378.

[237] Watkins T, Kumar A, Buttry DA. Designer ionic liquids for reversible electrochemical deposition/dissolution of magnesium. ] Am Chem Soc. 2016;138:641. 
[238] Kamath G, Narayanan B, Sankaranarayanan SKRS. Atomistic origin of superior performance of ionic liquid electrolytes for Al-ion batteries. Phys Chem Chem Phys. 2014;16:20387.

[239] Gifford PR. A substituted imidazolium chloroaluminate molten salt possessing an increased electrochemical window. ] Electrochem Soc. 1987;134:610.

[240] Zheng Y, Dong K, Wang Q, Zhang ], Lu X. Density, viscosity, and conductivity of Lewis acidic 1-butyl- and 1-hydrogen-3methylimidazolium chloroaluminate ionic liquids. J Chem Eng Data. 2013;58:32.

[241] Lang CM, Kim K, Guerra L, Kohl PA. Cation electrochemical stability in chloroaluminate ionic liquids. ] Phys Chem B. 2005;109:19454.

[242] Melton T], Joyce ], Maloy JT, Boon JA, Wilkes JS. Electrochemical studies of sodium chloride as a lewis buffer for room temperature chloroaluminate molten salts. J Electrochem Soc. 1990;137:3865.

[243] Vestergaard B, Bjerrum N], Petrushina I, Hjuler HA, Berg RW, Begtrup M. Molten triazolium chloride systems as new aluminum battery electrolytes. J Electrochem Soc. 1993;140:3108.

[244] Fannin AA, King LA, Levisky JA, Wilkes ]S. Properties of 1,3-dialkylimidazolium chloride-aluminum chloride ionic liquids. 1. Ion interactions by nuclear magnetic resonance spectroscopy. J Phys Chem. 1984;88:2609.

[245] Wilkes ]S, Levisky JA, Wilson RA, Hussey CL. Dialkylimidazolium chloroaluminate melts: a new class of room-temperature ionic liquids for electrochemistry, spectroscopy and synthesis. Inorg Chem. 1982;21:1263.

[246] Wang H, Bai Y, Chen S, Luo X, Wu C, Wu F, et al. Binder-free $\mathrm{V}_{2} \mathrm{O}_{5}$ cathode for greener rechargeable aluminum battery. ACS Appl Mater Interface. 2015;7:80.

[247] Jiang T, Chollier Brym M, Dubé G, Lasia A, Brisard G. Electrodeposition of aluminium from ionic liquids: part lelectrodeposition and surface morphology of aluminium from aluminium chloride $\left(\mathrm{AlCl}_{3}\right)$-ethyl-3-methylimidazolium chloride ([EMIm]Cl) ionic liquids. Surf Coat Technol. 2006;201:1.

[248] Jiang T, Brym MC, Dubé G, Lasia A, Brisard G. Electrodeposition of aluminium from ionic liquids: Part Il-studies on the electrodeposition of aluminum from aluminum chloride $\left(\mathrm{AICl}_{3]}\right.$ )-trimethylphenylammonium chloride (TMPAC) ionic liquids. Surf Coat Technol. 2006;201:10.

[249] Gale R], Osteryoung RA. Potentiometric investigation of dialuminum heptachloride formation in aluminum chloride-1butylpyridinium chloride mixtures. Inorg Chem. 1979;18:1603.

[250] Elia GA, Marquardt K, Hoeppner K, Fantini S, Lin R, Knipping E, et al. An overview and future perspectives of aluminum batteries. Adv Mater. 2016;28:7564.

[251] Xu M, Ivey D, Qu W, Xie Z. Study of the mechanism for electrodeposition of dendrite-free zinc in an alkaline electrolyte modified with 1-ethyl-3-methylimidazolium dicyanamide. J Power Sour. 2015;274:1249. 